OPEN ACCESS

Edited by:

Anna Santamaria,

Vall d'Hebron Research Institute,

Spain

Reviewed by:

Lionel Pintard,

Centre National de la Recherche

Scientifique (CNRS), France

Junmin Pan,

Tsinghua University, China

*Correspondence:

Arminja N. Kettenbach

arminja.n.kettenbach@dartmouth.edu

Specialty section:

This article was submitted to

Cell Growth and Division,

a section of the journal

Frontiers in Cell and Developmental

Biology

Received: 30 August 2017

Accepted: 06 November 2017

Published: 22 November 2017

Citation:

Rusin SF, Adamo ME and Kettenbach AN (2017) Identification of Candidate Casein Kinase 2

Substrates in Mitosis by Quantitative

Phosphoproteomics.

Front. Cell Dev. Biol. 5:97.

doi: 10.3389/fcell.2017.00097

\section{Identification of Candidate Casein Kinase 2 Substrates in Mitosis by Quantitative Phosphoproteomics}

\author{
Scott F. Rusin ${ }^{1}$, Mark E. Adamo ${ }^{2}$ and Arminja N. Kettenbach ${ }^{1,2 *}$ \\ ${ }^{1}$ Department of Biochemistry and Cell Biology, Geisel School of Medicine at Dartmouth, Hanover, NH, United States, ${ }^{2}$ Norris \\ Cotton Cancer Center, Dartmouth-Hitchcock Medical Center, Lebanon, NH, United States
}

Protein phosphorylation is a crucial regulatory mechanism that controls many aspects of cellular signaling. Casein kinase 2 (CK2), a constitutively expressed and active kinase, plays key roles in an array of cellular events including transcription and translation, ribosome biogenesis, cell cycle progression, and apoptosis. CK2 is implicated in cancerous transformation and is a therapeutic target in anti-cancer therapy. The specific and selective CK2 ATP competitive inhibitor, CX-4945 (silmitaseratib), is currently in phase 2 clinical trials. While many substrates and interactors of CK2 have been identified, less is known about CK2 substrates in mitosis. In the present work, we utilize CX4945 and quantitative phosphoproteomics to inhibit CK2 activity in mitotically arrested HeLa cells and determine candidate CK2 substrates. We identify 330 phosphorylation sites on 202 proteins as significantly decreased in abundance upon inhibition of CK2 activity. Motif analysis of decreased sites reveals a linear kinase motif with aspartic and glutamic amino acids downstream of the phosphorylated residues, which is consistent with known substrate preferences for CK2. To validate specific candidate CK2 substrates, we perform in vitro kinase assays using purified components. Furthermore, we identified CK2 interacting proteins by affinity purification-mass spectrometry (AP-MS). To investigate the biological processes regulated by CK2 in mitosis, we perform network analysis and identify an enrichment of proteins involved in chromosome condensation, chromatin organization, and RNA processing. We demonstrate that overexpression of CK2 in HeLa cells affects proper chromosome condensation. Previously, we found that phosphoprotein phosphatase 6 (PP6), but not phosphoprotein phosphatase 2A (PP2A), opposes CK2 phosphorylation of the condensin I complex, which is essential for chromosome condensation. Here, we extend this observation and demonstrate that PP6 opposition of CK2 is a more general cellular regulatory mechanism.

Keywords: CK2, proteomics, CX-4945, mitosis, phosphoproteomics, chromosome condensation

\section{INTRODUCTION}

Cells traversing mitosis undergo extraordinary changes in organization in order to equally divide genetic material and organelles between two daughter cells. In part, these changes are regulated by reversible phosphorylation by kinases and phosphatases. Over the course of their lifetime, at least three-quarters of all proteins are phosphorylated on one or more serine, threonine, or tyrosine 
residues (Cohen, 2000; Sharma et al., 2014). A tug-of-war between the opposing activities of kinases and phosphatases ensures the proper timing and coordination of events during mitotic progression. Control of nuclear envelope breakdown, golgi vesiculation and reformation, and chromosome condensation and segregation are key to a successful mitosis, and misregulation of any of these events can be detrimental to cells (Ottaviano and Gerace, 1985; Abe et al., 2011; Zhang et al., 2014). For instance, chromosome missegregation can lead to aneuploidy, a hallmark of human cancer (Rajagopalan and Lengauer, 2004; Hanahan and Weinberg, 2011). Although the majority of protein phosphorylation in mitosis has been attributed to master mitotic regulators, such as CDK1, Plk1, and Aurora A/B (Salaun et al., 2008), more recently roles for Casein kinase 2 (CK2) in the regulation of cell cycle transitions and mitosis have emerged (Takemoto et al., 2006; Yde et al., 2008; St-Denis et al., 2009, 2011; Li et al., 2010; Barrett et al., 2011; Peng et al., 2011).

Protein kinase CK2 is a highly conserved and constitutively expressed and active serine/threonine kinase found in all eukaryotes (Litchfield, 2003). CK2 regulates many cellular functions, including gene expression, translation, cell cycle progression and survival (Litchfield and Lüscher, 1993; Pinna and Meggio, 1997; Ahmed, 1999; Guerra and Issinger, 1999; Ahmed et al., 2002). CK2 is also overexpressed in a number of malignancies, and is a promising therapeutic target for several forms of cancer (Tawfic et al., 2001; Perea et al., 2008; Hanif et al., 2010; Siddiqui-Jain et al., 2010). In humans, CK2 is a heterotetrameric enzyme consisting of two catalytic $\alpha$ subunits ( $\alpha \alpha, \alpha \alpha,{ }^{\prime}$ or $\left.\alpha^{\prime} \alpha^{\prime}\right)$ and two regulatory $\beta$ subunits (Niefind et al., 2001). While many substrates of CK2 have been described, less is known about CK2 substrates in mitosis specifically.

Casein kinase 2 (CK2) has been implicated as a regulator of chromosome condensation (Takemoto et al., 2006). CK2 was shown to phosphorylate condensin I, a pentameric protein complex involved in chromosome compaction during mitosis (Takemoto et al., 2006). This phosphorylation inhibits condensin I activity in interphase until the G2/M transition, when these phosphorylation sites are removed by the phosphoprotein phosphatase PP6, resulting in condensin I activation (Rusin et al., 2015). Furthermore, CK2 has been shown to be necessary for the G1/S and G2/M transitions in Saccharomyces cerevisiae, and depletion of CK2 blocks cell cycle progression (Pepperkok et al., 1991, 1994; Lorenz et al., 1993; Glover, 1998). In mitosis, CK2 has been shown to phosphorylate Cdc25B, phosphoprotein phosphatase 2A (PP2A), HDAC1/2, and Topoisomerase II $\alpha / \beta$ (Hériché et al., 1997; Daum and Gorbsky, 1998; Escargueil et al., 2000; Theis-Febvre et al., 2003; Khan et al., 2013).

In recent years, many substrates of mitotic kinases have been identified through the use of specific and selective inhibitors combined with mass spectrometry-based phosphoproteomics (Kettenbach et al., 2011; Peng et al., 2011; Santamaria et al., 2011; Petrone et al., 2016). In this study we used a combination of the selective CK2 inhibitor CX-4945 and mass spectrometrybased phosphoproteomics as well as affinity purificationmass spectrometry (AP-MS) to systematically identify candidate CK2 substrates and CK2-dependent biological processes in mitotically-arrested HeLa cells. We validate specific candidate CK2 substrates in vitro, elaborate the role of CK2 in chromosome condensation in cells, and demonstrate a more general mechanism for phosphoprotein phosphatase 6 (PP6) opposition of CK2 phosphorylation.

\section{MATERIALS AND METHODS Cells}

HeLa and HEK-293T cells were grown as adherent cultures in Dulbecco's modified Eagle's media (DMEM, Cellgro Mediatech Inc.,) with $8 \%$ heat-inactivated FetalPlex (Gemini) and penicillinstreptomycin $(100 \mathrm{U} / \mathrm{ml}$ and $100 \mu \mathrm{g} / \mathrm{ml}$, respectively; Cellgro Mediatech Inc) at $37^{\circ} \mathrm{C}$ in a humidified incubator with $5 \%$ $\mathrm{CO}_{2}$. Sf9 cells were grown in Grace's supplemented insect cell media (LifeTechnologies) with $10 \%$ heat-inactivated fetal bovine serum (FBS) (Hyclone), $10 \mu \mathrm{g} / \mathrm{ml}$ gentamycin (SIGMA), and $0.25 \mu \mathrm{g} / \mathrm{ml}$ amphotericin B (SIGMA). Sf9 cells were maintained at $28^{\circ} \mathrm{C}$ in a non-humidified incubator.

For SILAC analysis, HeLa cells were grown in heavy or light DMEM (GIBCO) supplemented with 10\% dialyzed FBS (Hyclone) and penicillin-streptomycin. "Heavy" media contained $100 \mathrm{mg} / \mathrm{L}{ }^{13} \mathrm{C}_{6}{ }^{15} \mathrm{~N}_{2}$-lysine and $100 \mathrm{mg} / \mathrm{L}{ }^{13} \mathrm{C}_{6}{ }^{15} \mathrm{~N}_{4}$ arginine (Cambridge Isotope Laboratories), while "light" media contained $100 \mathrm{mg} / \mathrm{L}{ }^{12} \mathrm{C}_{6}{ }^{14} \mathrm{~N}_{2}$-lysine and $100 \mathrm{mg} / \mathrm{L}{ }^{12} \mathrm{C}_{6}{ }^{14} \mathrm{~N}_{4}$ arginine (Sigma). Cells were grown for a minimum of six doublings in the respective medium.

To synchronize cells in mitosis, thymidine ( $1 \mathrm{mM}$, Sigma) was added for $22 \mathrm{~h}$ to both conditions, followed by a $3 \mathrm{~h}$ washout with PBS (Corning) and subsequent addition of Taxol (Sigma) for $16 \mathrm{~h}$.

\section{Phosphoproteome-Wide Analysis of CK2 Inhibition}

For phosphoproteomic analysis, heavy and light cells were arrested in mitosis and treated with MG132 at a concentration of $10 \mu \mathrm{M}$ for $30 \mathrm{~min}$. Heavy-labeled HeLa cells were then treated with $5 \mu \mathrm{M}$ CX-4945, while light-labeled HeLa cells were treated with DMSO and incubated at $37^{\circ} \mathrm{C}$ for $45 \mathrm{~min}$. Mitotic HeLa cells were collected by mitotic shake-off, washed with PBS, snap frozen in liquid nitrogen, and stored at $-80^{\circ} \mathrm{C}$. Experiments were performed in biological triplicate. HeLa cell pellets were thawed on ice and lysed in ice-cold lysis buffer [ $8 \mathrm{M}$ urea, $25 \mathrm{mM}$ Tris- $\mathrm{HCl} \mathrm{pH} 8.6,150 \mathrm{mM} \mathrm{NaCl}$, phosphatase inhibitors (2.5 mM beta-glycerophosphate, $1 \mathrm{mM}$ sodium fluoride, $1 \mathrm{mM}$ sodium orthovanadate, $1 \mathrm{mM}$ sodium molybdate) and protease inhibitors (1 mini-Complete EDTA-free tablet per $10 \mathrm{ml}$ lysis buffer; Roche Life Sciences)] and sonicated three times for $15 \mathrm{~s}$ each with intermittent cooling on ice. Lysates were centrifuged at $15,000 \times g$ for $30 \mathrm{~min}$ at $4^{\circ} \mathrm{C}$. Supernatants were transferred to a new tube and the protein concentration was determined using a BCA assay (Pierce/ThermoFisher Scientific). For reduction, DTT was added to the lysates to a final concentration of $5 \mathrm{mM}$ and incubated for $30 \mathrm{~min}$ at $55^{\circ} \mathrm{C}$. Afterwards, lysates were cooled to room temperate and alkylated with $15 \mathrm{mM}$ iodoacetamide at room temperature for $45 \mathrm{~min}$. The alkylation was then quenched by the addition of an additional $5 \mathrm{mM}$ DTT. After 6-fold dilution with $25 \mathrm{mM}$ Tris- $\mathrm{HCl} \mathrm{pH} \mathrm{8,} \mathrm{the} \mathrm{samples} \mathrm{were} \mathrm{digested} \mathrm{overnight}$ 
at $37^{\circ} \mathrm{C}$ with $2.5 \%(\mathrm{w} / \mathrm{w})$ trypsin. The next day, the digest was stopped by the addition of $0.25 \%$ TFA (final v/v), centrifuged at $3,500 \times g$ for $30 \mathrm{~min}$ at room temperature to pellet precipitated lipids, and peptides were desalted on a $500 \mathrm{mg}$ (sorbent weight) SPE $\mathrm{C}_{18}$ cartridge (Grace-Davidson). Peptides were lyophilized and stored at $-80^{\circ} \mathrm{C}$ until further use.

\section{Phosphopeptide Enrichment}

Phosphopeptide purification was performed as previously described (Kettenbach and Gerber, 2011). Briefly, peptides were resuspended in $2 \mathrm{M}$ lactic acid in 50\% ACN ("binding solution"). Titanium dioxide microspheres were added and vortexed by affixing to the top of a vortex mixer on the highest speed setting at room temperature for $1 \mathrm{~h}$. Afterwards, microspheres were washed twice with binding solution and three times with $50 \%$ ACN/0.1\% TFA. Peptides were eluted twice with $50 \mathrm{mM} \mathrm{KH}_{2} \mathrm{PO}_{4}$ (adjusted to $\mathrm{pH} 10$ with ammonium hydroxide). Peptide elutions were combined, quenched with $50 \% \mathrm{ACN} / 5 \%$ formic acid, dried and desalted on a $\mu$ HLB OASIS $\mathrm{C}_{18}$ desalting plate (Waters).

\section{Pentafluorophenyl-Based Reversed Phase HPLC}

Offline PFP-based reversed phase HPLC fractionation was performed as previously described (Grassetti et al., 2017). Briefly, phosphopeptides were fractionated using a Waters XSelect HSS PFP $2.5 \mu \mathrm{m} 2.1 \times 150 \mathrm{~mm}$ column on an Agilent 1100 liquid chromatography system, buffer A was 3\% acetonitrile/0.1\% TFA, and buffer $\mathrm{B}$ was $95 \%$ acetonitrile/0.1\% TFA. Flow rate was $150 \mu \mathrm{l} / \mathrm{min}$ with a constant column temperature of $20^{\circ} \mathrm{C}$. Phosphopeptides were fractioned using a 60 min linear gradient from 8 to $45 \%$ acetonitrile and collected as 48 fractions between minutes 2 and 65, the 48 fractions were then combined into 24 total samples prior to drying in a SpeedVac and LC-MS/MS analysis.

\section{LC-MS/MS Analysis}

LC-MS/MS analysis for peptides and phosphopeptides was performed on a Q-Exactive Plus hybrid quadrupole Orbitrap mass spectrometer (Thermo Fisher Scientific, Bremen, Germany) equipped with an Easy-nLC 1000 (Thermo Fisher Scientific) and nanospray source (Thermo Fisher Scientific). Phosphopeptides were redissolved in 5\% ACN/1\% formic acid and loaded onto a trap column at $2,500 \mathrm{nl} / \mathrm{min}(1.5 \mathrm{~cm}$ length, $100 \mu \mathrm{m}$ inner diameter, ReproSil, $C_{18}$ AQ $5 \mu \mathrm{m} 200 \AA$ pore; Dr. Maisch, Ammerbuch, Germany) vented to waste via a micro-tee and eluted across a fritless analytical resolving column $(35 \mathrm{~cm}$ length, $100 \mu \mathrm{m}$ inner diameter, ReproSil, $\mathrm{C}_{18}$ AQ $3 \mu \mathrm{m} 200 \AA$ pore) pulled in-house (Sutter P-2000, Sutter Instruments, San Francisco, CA) with a 60 min gradient of 5-30\% LC-MS buffer B (LC-MS buffer A: $0.0625 \%$ formic acid, 3\% ACN; LC-MS buffer B: $0.0625 \%$ formic acid, 95\% ACN). The Q-Exactive Plus was set to perform an Orbitrap MS1 scan $(R=120 \mathrm{~K}$; AGC target $=2.5 \mathrm{e} 5$ ) from 350 to 1,500 Thomson, followed by HCD MS2 spectra on the most abundant precursor ions detected by Orbitrap scanning $(R=15 \mathrm{~K}$; AGC target $=40,000$; $\max$ ion time $=50 \mathrm{~ms}$ ) for $2.5 \mathrm{~s}$ before repeating the cycle. Precursor ions were isolated for HCD by quadrupole isolation at width =
0.6 Thomson, and HCD fragmentation at 30\% collision energy. Charge state 2, 3, and 4 ions were selected for MS2.

\section{Peptide Spectral Matching and Bioinformatics}

Raw data were searched using COMET (release version 2014.01) in high resolution mode (Eng et al., 2013) against a target-decoy (reversed) (Elias and Gygi, 2007) version of the human proteome sequence database (UniProt; downloaded 2/2013, 40,482 entries of forward and reverse protein sequences) with a precursor mass tolerance of $\pm 1 \mathrm{Da}$ and a fragment ion mass tolerance of 0.02 $\mathrm{Da}$, and requiring fully tryptic peptides $(\mathrm{K}, \mathrm{R}$; not preceding $\mathrm{P}$ ) with up to three miscleavages. Static modifications included carbamidomethylcysteine and variable modifications included: oxidized methionine, heavy lysine and arginine, phosphorylated serine, threonine, and tyrosine. Searches were filtered using orthogonal measures including mass measurement accuracy ( $\pm 3 \mathrm{ppm})$, Xcorr for charges from +2 through +4 , and $\mathrm{dCn}$ targeting a $<1 \%$ FDR at the peptide level. The probability of phosphorylation site localization was assessed using PhosphoRS (Taus et al., 2011). Quantification of LC-MS/MS spectra was performed using MassChroQ (Valot et al., 2011). Phosphopeptide ratios were adjusted for mixing errors based on the median of the $\log _{2} \mathrm{H} / \mathrm{L}$ distribution.

\section{Statistical Rationale and Data, Motif Analysis}

Phosphopeptides were filtered by their $\mathrm{H} / \mathrm{L} \log _{2}$ ratio averages $<-1$ and the corresponding $p<0.05$, which were calculated using a two tailed Student's $t$-test assuming unequal variance. These peptides were then subjected to motif determination using the Motif-X algorithm and visualized using Weblogo 3.0 (Crooks et al., 2004; Schwartz and Gygi, 2005; Chou and Schwartz, 2011). Motifs were generated using a $10 \%$ threshold for input data. Protein-protein interactions of proteins belonging to phosphopeptides with significant increase in phosphorylation occupancy were determined using the STRING database and analyzed in Cytoscape (Shannon et al., 2003; Szklarczyk et al., 2015). Edges represent protein-protein interactions based on the STRING database. GO analyses were performed in Cytoscape using BiNGO to test for ontology enrichment of biological processes and cellular components (Saito et al., 2012). To assess significance of enrichment of terms, a hypergeometric test and Benjamini \& Hochberg false discovery rate (FDR) correction were used. For a processes or component to be considered as “enriched," a corrected $P$-value cutoff of 0.05 was applied.

\section{CK2 $\alpha / \beta$ Cloning, Expression and Insect Cell Purification}

CK2 $\alpha$ and CK2 $\beta$ were amplified via PCR using the following primers:

$\begin{array}{ll}\text { CK2 } 2 \text { F } & 5^{\prime} \text {-ACGCGTCGACATGTCGGGACCCGTGCC } \\ & \text { AAG-3' } \\ \text { CK2 } 2 \text { R } & 5^{\prime} \text {-CCCAAGCTTTTACTGCTGAGCGCCAG } \\ & \text { CG- } 3^{\prime}\end{array}$




\section{CK2 $\beta$ F $\quad 5^{\prime}$-CGCGGATCCATGAGCAGCTCAGAGGAGG TG-3' \\ CK2 $\beta$ R 5'-CCGCTCGAGTCAGCGAATCGTCTTGAC TG-3'}

Both genes were cloned into the pFastBacl (Life Technologies) vector by restriction digest. CK $2 \alpha$ was cloned into a pFastBac1 vector containing a 10 -histidine tag while CK2 $\beta$ was cloned into pFastBacl with no tag. Constructs were sequenced and transformed into the $\mathrm{DH} 10 \propto$ E. coli strain to create bacmids. The resulting bacmid DNA was isolated, genotyped, and transfected into Sf9 cells to create recombinant baculovirus. For protein production, Sf9 cells were coinfected in a T75 dish with CK2 $\alpha$ 10his and CK2 $\beta$ viruses for $84 \mathrm{~h}$. Prior to collection, cells were treated with okadaic acid for $2 \mathrm{~h}$, collected, and washed in PBS. Cells were lysed in lysis buffer containing: $20 \mathrm{mM}$ HEPES pH 7.5, $150 \mathrm{mM} \mathrm{NaCl}, 5 \mathrm{mM} \beta$-glycerphosphate, $2 \mathrm{mM}$ sodium fluoride, $2 \mathrm{mM}$ sodium molybdate, $1 \mathrm{mM}$ sodium orthovanadate, 1\% CHAPS, $2.5 \mathrm{mM}$ EGTA, $5 \mathrm{mM}$ BME, $25 \mathrm{mM}$ imidazole and a protease inhibitor tablet. Samples were sonicated three times for $15 \mathrm{~s}$ each. Cell lysate was clarified at $8,000 \times g$ at $4^{\circ} \mathrm{C}$ for $30 \mathrm{~min}$. Nickel-NTA agarose resin previously washed in lysis buffer was added to the clarified lysate for $2 \mathrm{~h}$ with rotation at $4^{\circ} \mathrm{C}$. Kinase complex bound nickel-NTA agarose was washed twice with lysis buffer, twice with wash buffer (lysis buffer with additional $500 \mathrm{mM} \mathrm{NaCl}$ ), followed by elution in $200 \mu \mathrm{L}$ of elution buffer (lysis buffer with additional $400 \mathrm{mM}$ imidazole and $1 \mathrm{mM}$ EDTA). Elutions were dialyzed against in vitro kinase assay buffer containing $5 \mathrm{mM}$ HEPES pH 7.5, $125 \mathrm{mM} \mathrm{NaCl}, 0.25 \mathrm{mM}$ EDTA, and $0.5 \mathrm{mM}$ DTT.

\section{CK2 Subunit Cloning for Immunoprecipitation}

Subunits of CK2 were amplified via PCR using the following primers:

$\begin{array}{ll}\text { CK2 } \alpha & 5^{\prime} \text {-CCCAAGCTTATGTCGGGACCCGTGCCAAG } \\ & \text { CAGG-3' } \\ \text { CK2 } \alpha & 5^{\prime} \text {-CGCGGATCCTTACTGCTGAGCGCCAGCGG } \\ & \text { CAG-3' } \\ \text { CK2 } \beta & 5^{\prime} \text {-CCCAAGCTTATGAGCAGCTCAGAGGAGGT } \\ & \text { GTC-3' } \\ \text { CK2 } \beta & 5^{\prime} \text {-CGCGGATCCTCAGCGAATCGTCTTGACTG } \\ & \text { GGCTC-3' } \\ \text { CK2 } \alpha^{\prime} & 5^{\prime} \text {-CCCAAGCTTATGCCCGGCCCGGCCGC } \\ & \text { GG-3' } \\ \text { CK2 } \alpha^{\prime} & 5^{\prime} \text {-CGCGGATCCTCATCGTGCTGCCGTGAGAC } \\ & \text { CAC-3' }\end{array}$

All genes were cloned into the p3xFLAG-CMV-10 (SIGMA) vector using restriction digests. Constructs were sequenced to confirm identities. Vectors were then transfected into HEK-293T cells which were subsequently arrested in mitosis as described above. Cells were lysed in FLAG lysis buffer containing $50 \mathrm{mM}$ Tris- $\mathrm{HCl} \mathrm{pH}$ 7.5, $150 \mathrm{mM} \mathrm{NaCl}, 1 \%$ Triton-X100 and a protease inhibitor tablet. Samples were sonicated three times for $15 \mathrm{~s}$ each. Cell lysate was clarified at $8,000 \times g$ at $4^{\circ} \mathrm{C}$ for $15 \mathrm{~min}$. AntiFLAG M2 affinity gel (SIGMA) previously washed in FLAG lysis buffer was applied to the clarified lysate for $2 \mathrm{~h}$ with rotation at $4{ }^{\circ} \mathrm{C}$. Bound resin was then washed three times with FLAG lysis buffer and eluted in $30 \mu \mathrm{l}$ TBS with $0.16 \mu \mathrm{g} / \mu \mathrm{l} 3 \mathrm{xFLAG}$ peptide by vortexing gently for $30 \mathrm{~min}$ at $4^{\circ} \mathrm{C}$. Elutions were then Trichloroaceitic acid (TCA) precipitated. Briefly, samples were diluted in 20\% TCA, incubated on ice for $15 \mathrm{~min}$, and centrifuged at $21,100 \times g$ for $15 \mathrm{~min}$ at $4^{\circ} \mathrm{C}$. Samples were resuspended in $10 \%$ TCA and centrifuged at $21,100 \times g$ for $10 \mathrm{~min}$ at $4^{\circ} \mathrm{C}$. This step was repeated once more. Samples were then resuspended in cold acetone and centrifuged at $21,100 \times g$ for $10 \mathrm{~min}$ at $4^{\circ} \mathrm{C}$. This step was repeated once more. Samples were air-dried and processed for LC-MS/MS analysis.

\section{Purification of Substrates from E. coli}

Substrates were amplified via PCR using the following primers:

$\begin{array}{ll}\text { EF1D F } & \text { 5'-CCGCTCGAGGCTACAAACTTCCTAGC } \\ & \text { AC-3' } \\ \text { EF1D R } & 5^{\prime} \text {-AAGGAAAAAAGCGGCCGCTCAGATC } \\ & \text { TTGTTGAAAG-3' } \\ \text { HAP28 F } & 5^{\prime} \text {-CCGCTCGAGCCTAAAGGAGGAAGAA } \\ & \text { AG-3' } \\ \text { HAP28 R } & 5^{\prime} \text {-AAGGAAAAAAGCGGCCGCTTACTTA } \\ & \text { TTCAGGGAG-3' } \\ \text { S30BP F } & 5^{\prime} \text {-CCGCTCGAGGCGGGGAAGAAGAATGT } \\ & \text { TC-3' } \\ \text { S30BP R } & 5^{\prime} \text {-AAGGAAAAAAGCGGCCGCTCACTGCT } \\ & \text { TGGCCTTC-3' }\end{array}$

Each substrate was cloned into the pET16b vector containing a 10x-His tag. The constructs were sequenced and transformed into BL21 (DE3) pLys E. coli. Colonies were grown overnight in LB liquid medium containing $0.1 \mathrm{mg} / \mathrm{mL}$ of ampicillin at $37^{\circ} \mathrm{C}$ to saturation. Cultures were then diluted into LB liquid medium containing $0.1 \mathrm{mg} / \mathrm{mL}$ ampicillin and grown at $37^{\circ} \mathrm{C}$ until an OD600 reading of 0.6. Cultures were then induced with $1 \mathrm{mM}$ IPTG and moved to $18^{\circ} \mathrm{C}$ overnight. Soluble proteins were purified under native conditions. Pellets were resuspended in $\sim 6-7 \mathrm{~mL}$ of lysis buffer containing: $50 \mathrm{mM} \mathrm{NaH}_{2} \mathrm{PO}_{4}, 300 \mathrm{mM}$ $\mathrm{NaCl}$, and $10 \mathrm{mM}$ imidazole $\mathrm{pH}$ 8. Cells were sonicated, precleared, and incubated with nickel-NTA beads (Qiagen) for $3 \mathrm{~h}$ at $4^{\circ} \mathrm{C}$. Beads were collected and washed in wash buffer containing: $50 \mathrm{mM} \mathrm{NaH} \mathrm{PO}_{4}, 300 \mathrm{mM} \mathrm{NaCl}, 20 \mathrm{mM}$ imidazole $\mathrm{pH}$ 8. The beads were eluted with $100 \mu \mathrm{L}$ of elution buffer containing: $50 \mathrm{mM} \mathrm{NaH}_{2} \mathrm{PO}_{4}, 300 \mathrm{mM} \mathrm{NaCl}, 500 \mathrm{mM}$ imidazole $\mathrm{pH}$ 8. Purified protein was dialyzed overnight in dialysis buffer containing: $10 \mathrm{mM}$ HEPES-KOH pH 7.7, $100 \mathrm{mM} \mathrm{NaCl}, 1 \mathrm{mM}$ DTT, 0.1 mM EDTA, 10\% glycerol.

\section{CK2 in Vitro Kinase Assay}

Kinase assays containing $75 \mathrm{ng}$ of $\mathrm{CK} 2 \alpha / \beta, 1 \mu \mathrm{g}$ of purified substrate, $50 \mathrm{mM}$ HEPES pH 7.5, $10 \mathrm{mM} \mathrm{NaCl}, 2 \mathrm{mM}$ DTT, $1 \mathrm{mM} \mathrm{MnCl} 2,0.01 \%$ Brij 35 and $100 \mu \mathrm{M}$ ATP were placed at $28^{\circ} \mathrm{C}$ for $2 \mathrm{~h}$, followed by addition of $50 \mathrm{mM}$ Tris- $\mathrm{HCl}, \mathrm{pH} 8.6$ containing $1 \%$ SDS. Reactions were dialyzed overnight against in-vitro kinase assay buffer without ATP to inactive CK2 in reactions. 


\section{PP6 in Vitro Phosphatase Assay}

HEK-293T cells were transfected with p3xFlag-CMV10-PP6c and stable cells lines were selected using G418. Purification of PP6c holoenzymes was performed using anti-Flag M2 affinity gel (SIGMA) (15 $\mu \mathrm{l}$ resin for each $15 \mathrm{~cm}$ tissue culture dish lysed) and eluted with 3xFLAG-peptide (final concentration $150 \mathrm{ng} / \mu \mathrm{l}$ ). For dephosphorylation reactions, substrates were incubated in the presence or absence of PP6c holoenzymes in phosphatase buffer (50 mM HEPES pH 7.5, $10 \mathrm{mM} \mathrm{NaCl,} 2 \mathrm{mM}$ DTT, $1 \mathrm{mM}$ $\mathrm{MnCl}_{2}, 0.01 \%$ Brij 35) and incubated for $2 \mathrm{~h}$ at $28^{\circ} \mathrm{C}$. Reactions were quenched by the addition of SDS-PAGE sample buffer, reduced and alkylated (as described above), and separated by SDS-PAGE gel electrophoresis. Substrate bands were excised and digested with trypsin (for EF1D, HAP28, and S30BP) in $25 \mathrm{mM}$ ammonium bicarbonate overnight at $37^{\circ} \mathrm{C}$ or Proteinase $\mathrm{K}$ (for NCAP-D2) in $50 \mathrm{mM}$ TEAB for $1 \mathrm{~h}$ at $37^{\circ} \mathrm{C}$. Peptides were extracted using $5 \%$ formic acid/50\% ACN and dried. NCAP-D2 peptides were labeled heavy and light by reductive dimethylation (as described above), mixed, and desalted. Peptides were analyzed on a Q-Exactive Plus mass spectrometer (Thermo Scientific) or Orbitap Fusion mass spectrometer equipped with an EasynLC 1000 (Thermo Scientific). Raw data were searched using COMET in high resolution mode (Eng et al., 2013) against a condensin I sequence database with a precursor mass tolerance of $\pm 20 \mathrm{ppm}$, no enzyme specificity, carbamidomethylcysteine, and dimethylation at peptide amino-termini and lysines, as fixed modifications. Oxidized methionine, phosphorylated serine, threonine and tyrosine, isotopically heavy label $(+8.04437)$ at peptide amino-termini and lysines, were searched as variable modifications. Probability of phosphorylation site localization was determined by PhosphoRS (Taus et al., 2011). Quantification of LC-MS/MS spectra was performed using MassChroQ (Valot et al., 2011).

\section{Chromosome Spreads}

CK2 $\alpha$ expression in HeLa-FLP was induced by addition of doxycycline for $48 \mathrm{~h}$, and then cells were treated for $4 \mathrm{~h}$ with $100 \mathrm{ng} / \mathrm{mL}$ nocodazole. Cells were collected by mitotic shakeoff and pelleted. Cells were resuspended gently in $75 \mathrm{mM}$ $\mathrm{KCl}$, incubated at room temperature for $5 \mathrm{~min}$ and at $4^{\circ} \mathrm{C}$ for $1 \mathrm{~min}$ and pelleted by centrifugation. Cells were fixed with methanol:acetic acid (3:1) and pelleted. Cells were washed twice with methanol:acetic acid (3:1), resuspended and dropped onto glass slides. Slides were allowed to dry and DNA was stained with NucBlue Fixed Cell ReadyProbes reagent (Life Technologies) diluted in PBS for $30 \mathrm{~min}$ and sealed with coverslips using ProLong Gold (Life Technologies). Experiments were done in biological triplicates. At least 300 chromosome spreads were counted per condition and experiment.

\section{RESULTS}

\section{Phosphoproteomic Profiling of Mitotic HeLa Cells Treated with CX-4945}

To determine the efficacy of CX-4945 in inhibiting CK2, HeLa cells were treated cells with either various concentrations of CX-4945 for $1 \mathrm{~h}$ or at a concentration of $5 \mu \mathrm{M}$ for different lengths of time to establish an optimal dose and time for treatment (Figure 1A). Cells were collected, lysed and analyzed by western blotting using an antibody against the pan-CK2 phosphorylated consensus motif. Based on this analysis, as well as previously published reports, we chose to treat cells with $5 \mu \mathrm{M} \mathrm{CX}-4945$ for $45 \mathrm{~min}$ (Siddiqui-Jain et al., 2010). To identify candidate CK2 substrates, HeLa cells were metabolically-labeled using growth media containing light or heavy arginine and lysine (SILAC) (Figure 1B; Supplementary Figure 1; Ong et al., 2002), synchronized in the cell cycle with a thymidine block, released from the block and arrested in mitosis using the microtubule stabilizer Taxol. Mitotically-arrested cells were treated with the proteasome inhibitor MG-132 for 30 min to block protein degradation upon inhibitor addition. Subsequently, heavy-labeled cells were treated with CX-4945 for $45 \mathrm{~min}$, while light-labeled cells were controltreated with DMSO. After $45 \mathrm{~min}$, cells were collected, mixed 1:1 based on cell counting, lysed and protein digested with trypsin. Phosphopeptides were enriched using titanium dioxide microsphere enrichment, fractionated by pentafluorophenyl reverse-phase separation and analyzed by liquid chromatography coupled to tandem mass spectrometry (LC-MS/MS) (Figure 1B). These phosphoproteomic experiments were conducted in biological triplicates.

Using this approach, we were able to identify 30,345 phosphopeptides corresponding to 23,995 unique phosphorylation sites on 5,060 proteins. Of these, 23,466 phosphopeptides corresponding to 18,603 unique phosphorylation sites on 4,306 proteins were quantified. The majority of phosphopeptides, $88 \%$, were quantified in at least two of three biological replicates (Supplementary Table 1). To assess the reproducibility of quantification of phosphorylation site changes upon addition of CX-4945, we performed statistical analysis using Student's T-test (Figure 2A). In total 4,659 phosphopeptides were quantified with a $p<0.05$. Of these statistically significant sites, 330 phosphopeptides corresponding to 287 phosphorylation sites on 202 proteins decreased by 2 -fold or more $\left(\log _{2}\right.$ ratio $<-1$ ), while 150 phosphopeptides corresponding to 144 phosphorylation sites on 116 proteins increased by 2 -fold or more $\left(\log _{2}\right.$ ratio $\left.>1\right)$ in abundance upon inhibition of CK2.

Next, we performed linear motif analysis of amino acids surrounding the phosphorylation site for sites that decreased in phosphorylation upon CK2 inhibition. In this analysis, we found an enrichment for an acidophilic motif with a glutamic or aspartic acid residue in the +1 and/or +3 positions downstream as well as a preference of acidic amino acids upstream of the phosphorylated residue (Figure 2B), which is consistent with the previously reported linear motif preference of CK2 (Marin et al., 1986; Meggio et al., 1994). We also detected a proline-directed motif in $14 \%$ of the significantly changed phosphopeptides (Figure 2B). It was previously reported that a proline-directed motif is incompatible with direct phosphorylation of $\mathrm{CK} 2$, but that proline-directed phosphorylation sites can prime for CK2 phosphorylation (Marin et al., 1992; St-Denis et al., 2015). Because most of the proline-directed phosphorylation sites that decreased upon 


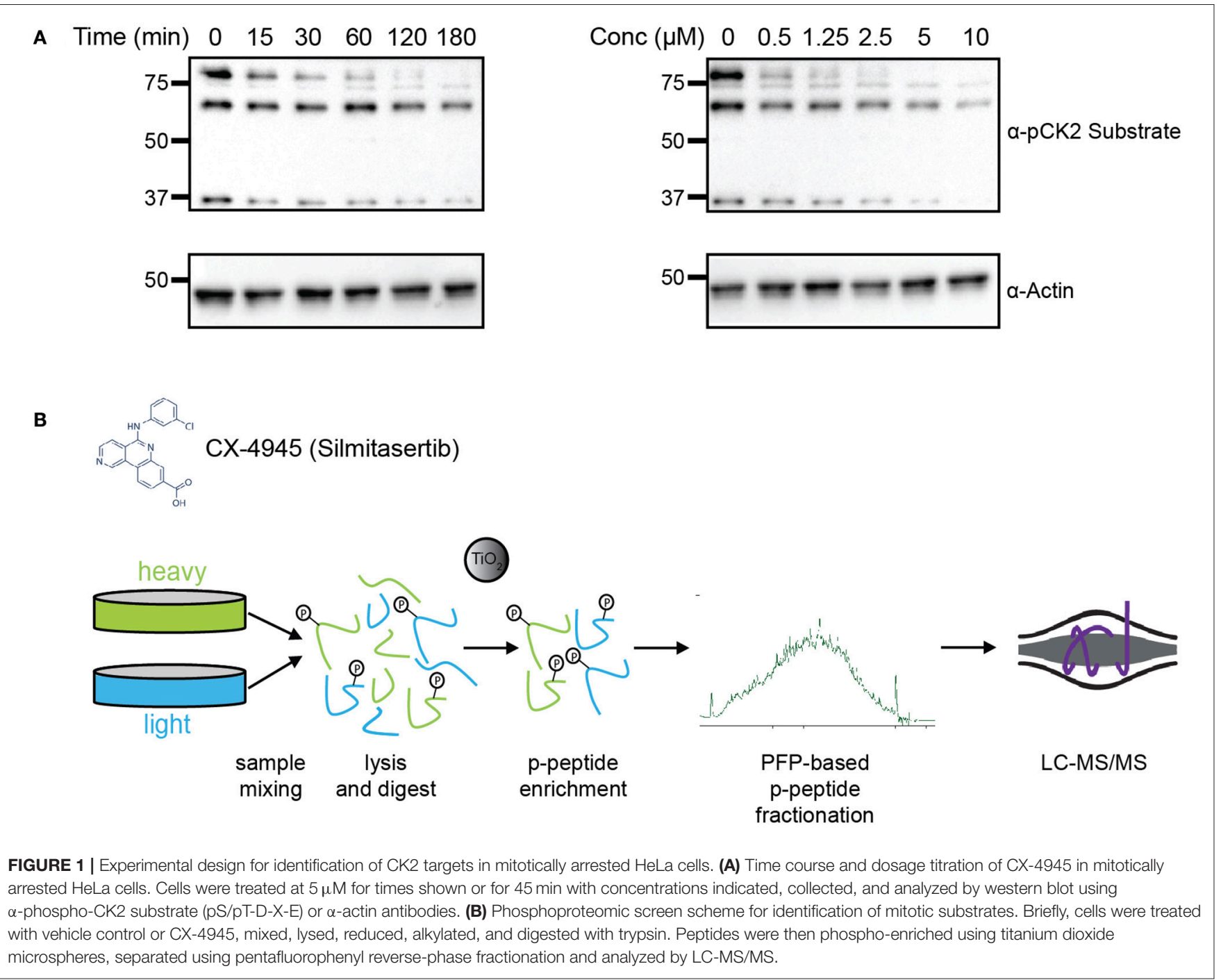

CK2 inhibition were single phosphorylation sites, they are not likely to be part of a priming mechanism. Thus, we believe that these sites are either due to an off-target effect of CX4945 or are an indirect result of CK2 inhibition and excluded these sites from consideration as candidate CK2 phosphorylation sites.

Among the sites identified as sensitive to CX-4945 treatment, several have been previously confirmed as bona fide CK2 substrates when compared to the PhosphositePlus database (Hornbeck et al., 2015). These candidate CK2 substrates included topoisomerase II $\alpha$ (serine 1377), the translation initiation factor EIF2 $\beta$ (serine 2), the heat shock protein HSP90A serine 263), the elongation factor EF1D (serine 162), the histone deacetylase HDAC1 (serine 421 and serine 423), as well as the inhibitor of protein phosphatase 1 PPP1R2 (serine 121 and serine 122).

\section{Network Analysis of Candidate CK2 Substrates}

We next determined specific biological processes regulated by CK2 in mitosis via network analysis of proteins that contain significantly decreased phosphorylation site with acidophilic motif. We gathered protein-protein interaction data from the STRING database (Search Tool for the Retrieval of Interacting Genes/Proteins) and analyzed these interactions in Cytoscape (Shannon et al., 2003; Saito et al., 2012; Szklarczyk et al., 2015). We identified highly connected clusters of proteins within the candidate substrates, which were enriched for specific biological processes (Figure 3A). The cluster in gold showed enrichment for rRNA processing and ribosomal biogenesis and contained proteins mainly localized to the ribonucleoprotein complexes (Figure 3B). In Saccharomyces cerevisiae, CK2 is a component of the pre-ribosome, where together with Tor1 it was implicated in pre-rRNA processing switching (Kos-Braun et al., 2017). This cluster also contains members of the EIF2 complex, including member EIF2 $\beta$ (EIF2S2) and EIF2S3. CK2 has been previously shown to be phosphorylated EIF2 $\beta$ on serine 2, a site also identified in our study, to activate the protein and stimulate mRNA production and cell growth (Llorens et al., 2006). We also identify another translation initiation factor, EIF5B, as a potential substrate of CK2. In Saccharomyces cerevisiae CK2 has 


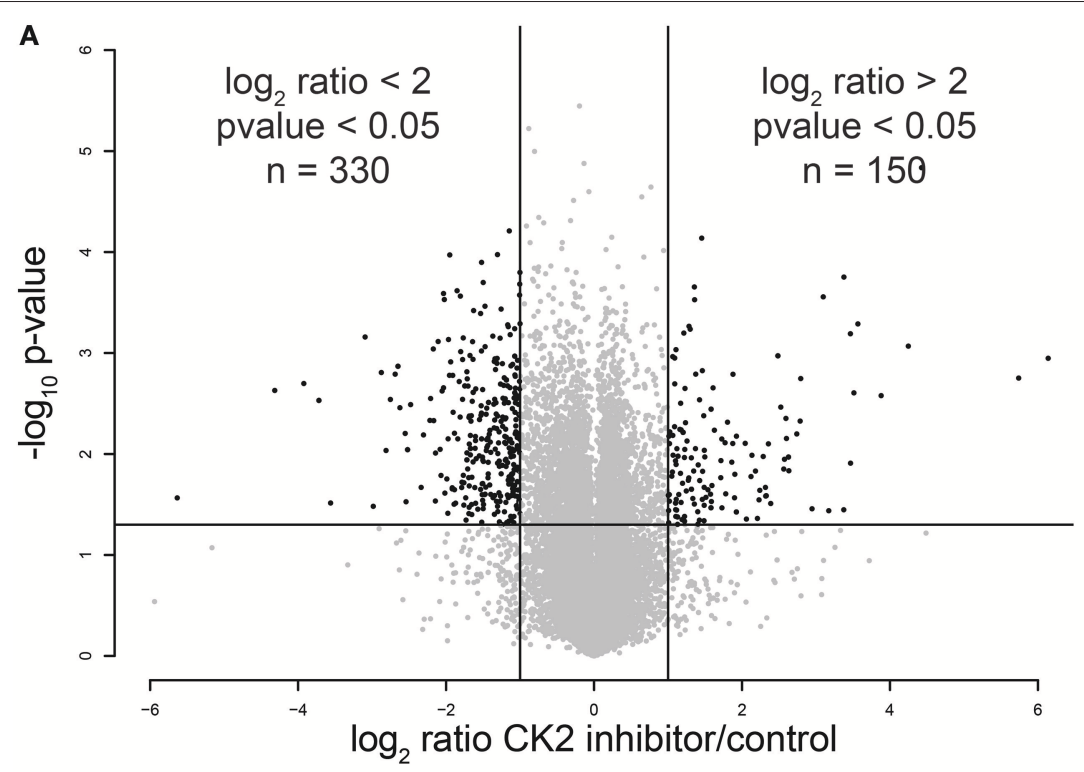

B

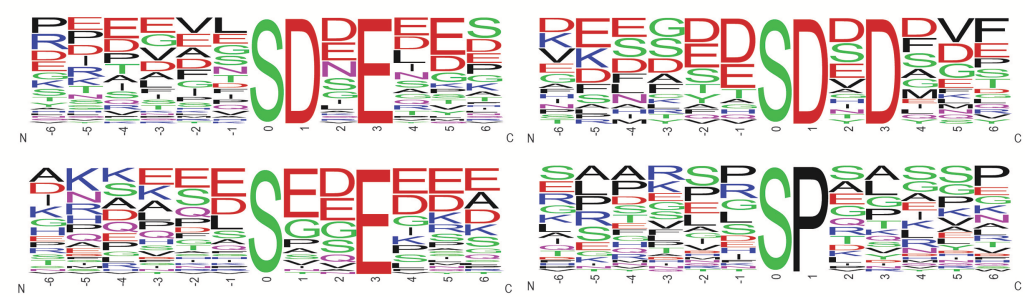

FIGURE 2 | Statistical and motif analysis of candidate substrates. (A) Volcano plot of $\log _{2}$ phosphopeptide ratios vs. the negative $\log _{10}$ of the $p$-value of the replicate fold change. (B) Significantly enriched motifs from phosphorylation sites decreased by 2-fold or more upon CK2 inhibition.

been shown to phosphorylate EIF5, although the functions of this phosphorylation are currently unknown (Maiti et al., 2003). The blue cluster showed enrichment for RNA splicing and members of the spliceosomal complex. It has been previously shown that CK2 phosphorylation of proteins involved in catalyzing the splicing reaction increases their association with the spliceosome as well as the activity of the spliceosome itself (Kim et al., 2014). The cluster in black represents proteins that contribute to chromosome condensation that localize to chromosomes. Among those proteins are members of the condensin I complex, including NCAPG, NCAPD2, as well as SMC4, a protein shared between the condensin I and II complex. CK2 phosphorylation of condensin I complex members is known to inhibit its activity (Takemoto et al., 2006). In addition, we identify phosphorylation sites on both topoisomerase II $\alpha$, a known substrate of CK2 and topoisomerase II $\beta$, a known interactor of CK2 $\beta$ (Escargueil et al., 2000; Park et al., 2001). Interestingly the role of this specific phosphorylation site on topoisomerase $\mathrm{II} \alpha$ remains unknown. The fourth and final cluster in purple includes proteins involved with chromatin organization. Included in this group is the histone deacetylase HDAC1. CK2 phosphorylation of HDAC1 and HDAC2 is required for the dissociation of both proteins from each other and formation of HDAC1 and HDCA2 homodimers (Tsai and Seto, 2002; Khan et al., 2013). In our study we identify both sites on HDAC1 that have been implicated in this process, serine 421 and serine 423 , as well as an additional phosphorylation site, serine 393 , which has a currently unknown function. We also identify a phosphorylation site on the methyltransferase DNMT3B, S136. CK2 has been shown to phosphorylate DNM3TA and reduce its methyltransferase activity, however, the effect of CK2 phosphorylation of DNMT3B remains to be determined (Deplus et al., 2014). Also contained in this group is PPP1R2, a negative regulator of protein phosphatase PP1 and known substrate of CK2 as mentioned previously through database mining (Korrodi-Gregório et al., 2013). However, the precise role for these phosphorylation sites remains unknown.

\section{Analysis of CK2 Interactome in Mitotic HEK-293T Cells}

To further investigate CK2 regulated biological processes in mitosis, we identified proteins that interact with CK2 complex subunits in mitotic human cells. CK2 forms heterotetramers composed of two catalytic subunits ( $\alpha$ or $\alpha$, either as homoor heterodimer) and two regulatory $\beta$ subunits (Figure 4A). We generated FLAG-tagged CK2 $\alpha$, CK2 $\alpha$, and CK2 $\beta$ constructs, transiently transfected them into HEK-293T cells, arrested cells 


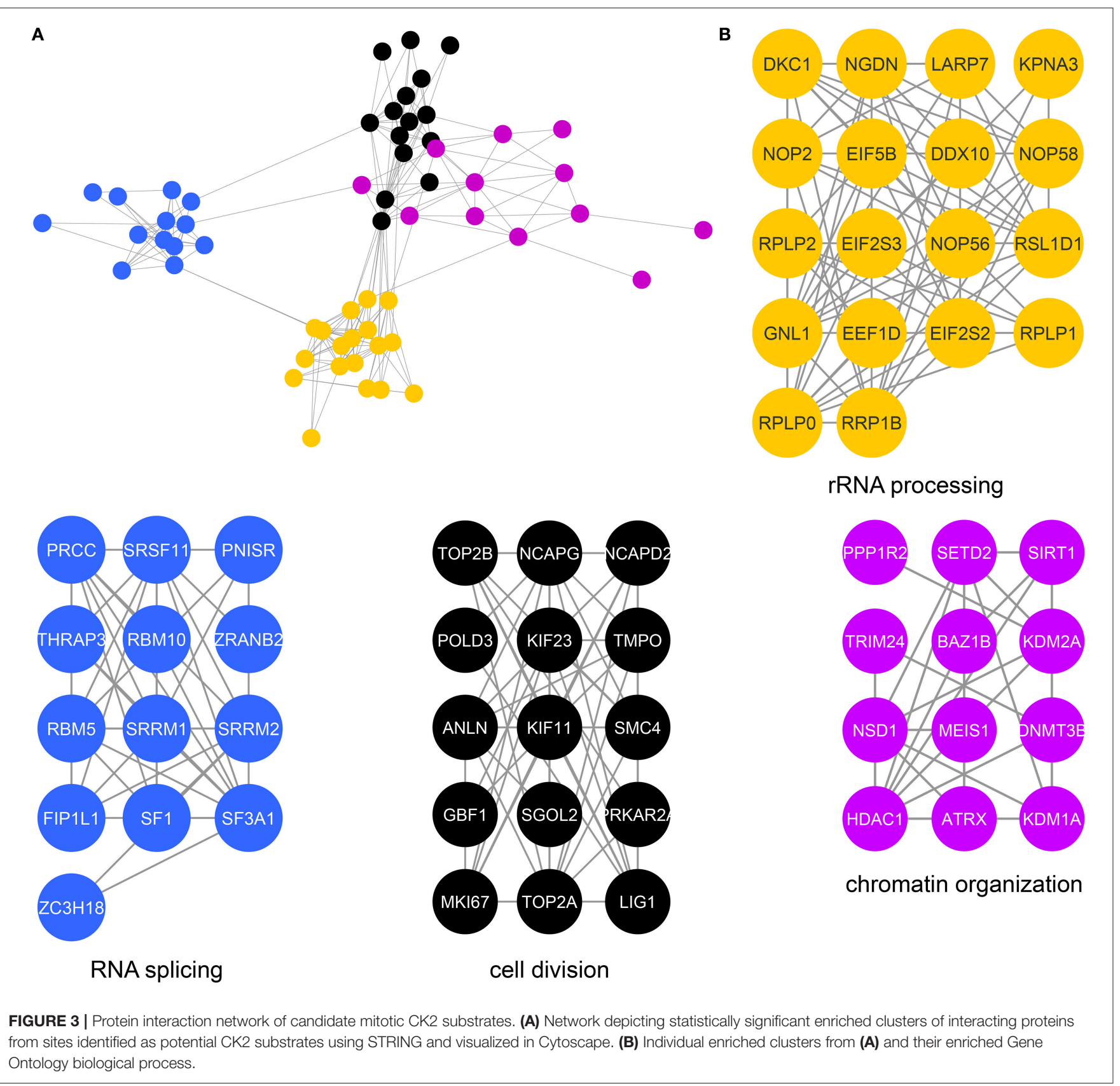

in mitosis with Taxol and performed affinity purificationmass spectrometry (AP-MS) analyses to determine interactors for each subunit (Figure 4B). All analyses were performed in quadruplicate. In these analyses, we identified 315 significant interactions compared to control for all subunits combined that were enriched 3-fold or more above control pull-downs (Figure 4C). Of those interactions the majority $(184 / 315,58.5 \%)$ interacted with only CK2 $\beta$, with CK2 $\alpha$ ' having fewer $(44 / 315$, $14.1 \%)$ and $\mathrm{CK} 2 \alpha$ having the fewest subunit-specific protein interactions $(5 / 315,0.2 \%)$ (Supplementary Table 2$)$. The other interacting proteins $(82 / 315,26.1 \%)$ were identified in AP-MS analyses of two or more subunits. We then investigated CK2 interactors using the STRING database and Cytoscape for their connectivity and identified eight distinct nodes (Figure 5A).

The most highly enriched cluster (gold) included proteins involved in rRNA processing (Figure 5B). Several interactors in this group were also identified as substrates (Figure 3B), including the RNA helicase DDX10, the guanine nucleotide binding protein GNL1 and RRP1B, a ribosomal RNA processing protein which has been linked as a susceptibility marker in breast cancer (Lee et al., 2014). The second most significant set of interactors (purple) harbored proteins involved in chromatin organization, again overlapping with proteins identified as substrates (Figure 3B). For instance, BAZ1B and SETD2 are 
A

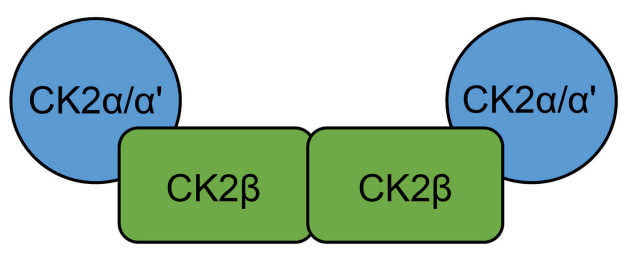

B

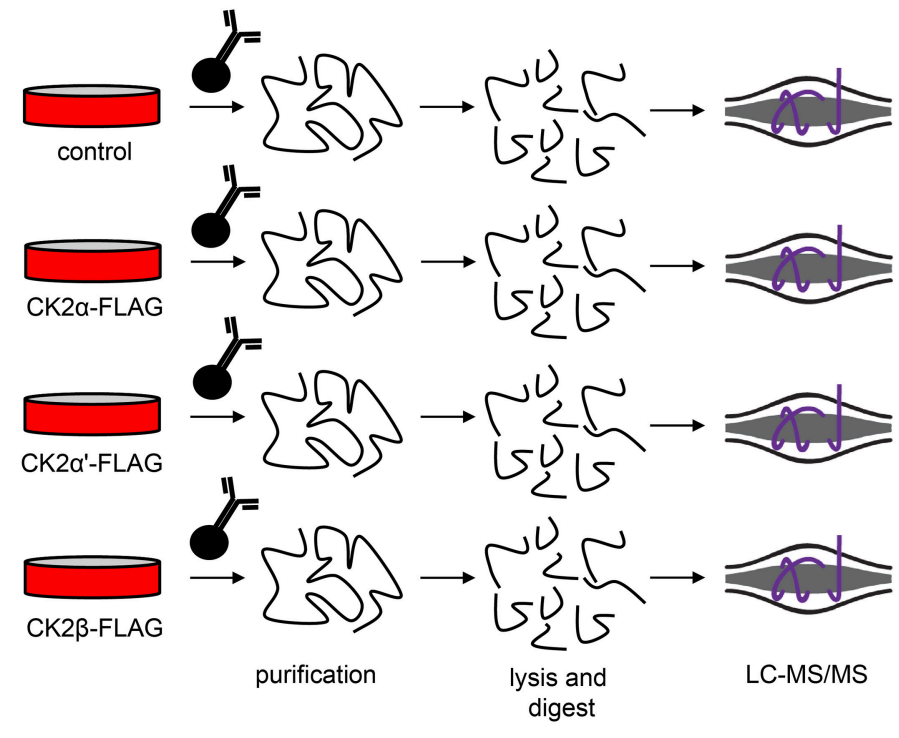

C
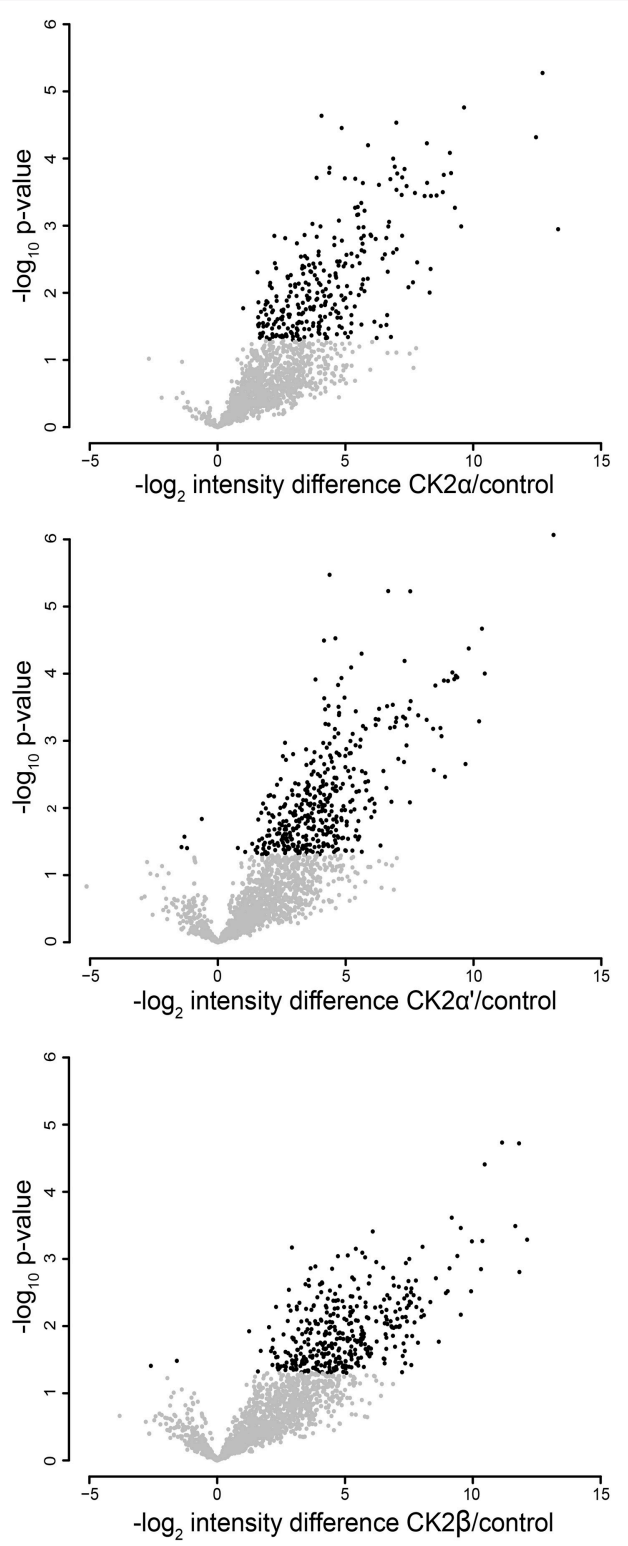

FIGURE 4 | Mitotic CK2 AP-MS analysis. (A) Scheme depiction of tetrameric CK2 complex found in cells. (B) Scheme for identification of mitotic CK2 interactors. Cells were transfected with different FLAG-tagged CK2 subunits or control and mitotically arrested. Cells were collected, lysed, and FLAG-tagged proteins were purified, TCA precipitated, and analyzed by LC-MS/MS. (C) Volcano plots of the $\log _{2}$ difference in intensity between sample and control against the negative log 10 of the $p$-value of the replicate fold change for each of the three purifications performed.

candidate substrates as well as interactors. In addition, we identified a large number of DNA helicases [chromodomainhelicase-DNA-binding-protein (CHD) 1, 2, 3, 6, 7, 8, and 9]. These proteins play key roles in chromatin remodeling, a process that $\mathrm{CK} 2$ has been implicated in regulating in Saccharomyces cerevisiae (Barz et al., 2003). These proteins also interact with another protein in this group, SUPT6H, which itself has been shown to interact with IWS1, a putative CK2 substrate identified in our screen, and implicated in mRNA processing (Yoh et al., 2007). While no phosphorylation sites were identified for SUPT6H or the CHD proteins identified as interactors, it is possible that these proteins could target CK2 to IWS1 to promote phosphorylation. A smaller cluster of interacting proteins (blue) belongs to proteins involved in RNA splicing, which was also overlapping with enriched biological processes identified in the substrate analysis. Here, we identified members of the small nuclear RNA-activating protein (SNAP) complex, including SNAPC1, SNAPC3 and SNAPC4. It was previously demonstrated that CK2 phosphorylates SNAPC4 and this phosphorylation leads to loss in SNAPC4 DNA binding and loss of U6 transcriptional activity (Gu et al., 2007). A number of general splicing factors were also identified, such as SLU7, 
A

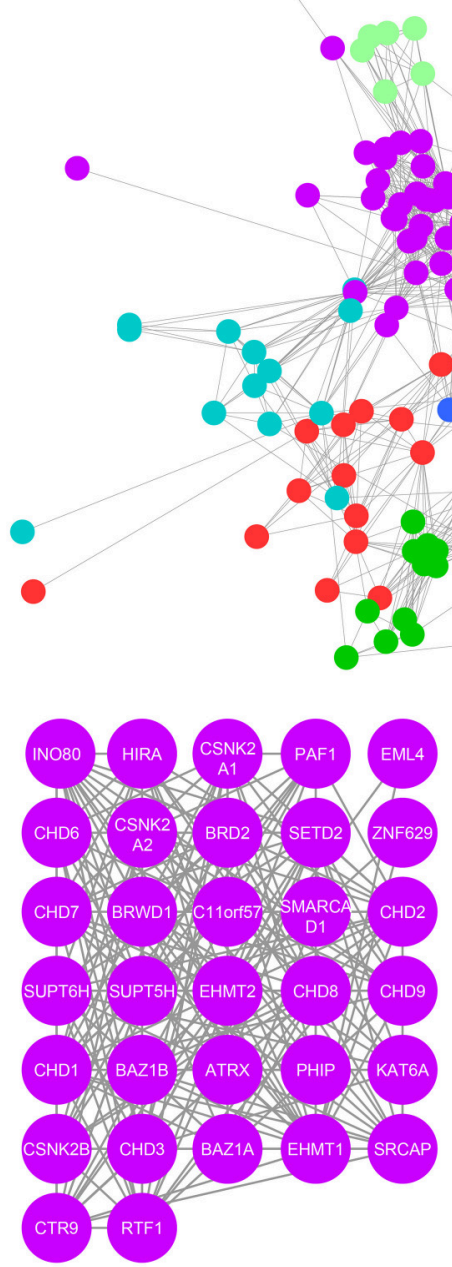

chromatin organization
B

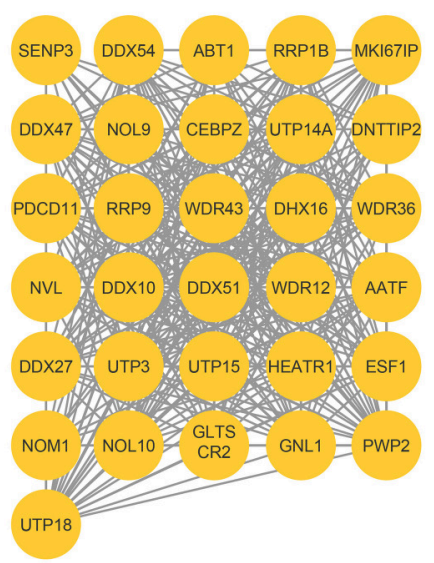

rRNA processing

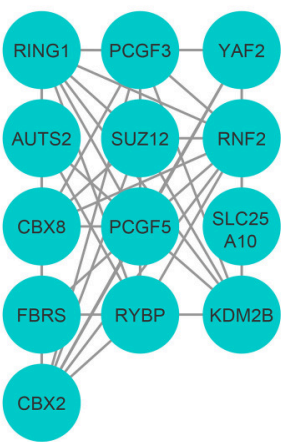

histone ubiquitination

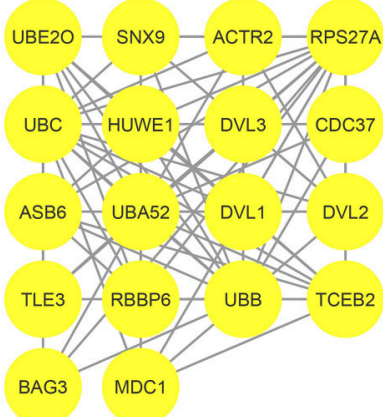

Wnt receptor signaling pathway

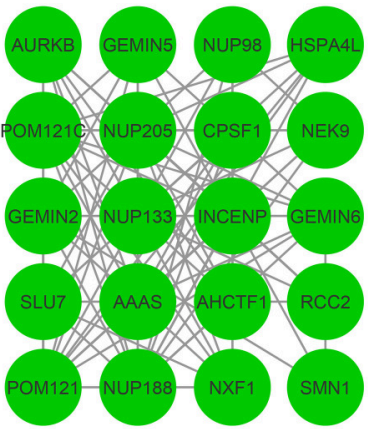

mRNA transport

FIGURE 5 | Protein interaction network of mitotic CK2 interactors. (A) Network depicting statistically significant enriched clusters of interacting proteins from CK2-interacting proteins identified by two or more peptides whose abundance increased 3-fold or more over control. (B) Individual enriched clusters from (A) and their enriched Gene Ontology biological process. 
DHX16, and MFAP1, which again agrees with a general role for CK2 in mRNA splicing (Lehnert et al., 2008). Another cluster of tightly-associated interactors (red) included proteins involved in cell division, for instance members of the condensin I complex including (NCAPD2 and NCAPH). We also identify several proteins with known roles in spindle dynamics, including Aurora A kinase (AURKA), the kinesin KIF20A, and the microtubule binder ASPM (Neef et al., 2003; Floyd et al., 2008; Jiang et al., 2017). ASPM is identified as both an interactor and a candidate substrate of CK2, with phosphorylation of serine 35 decreasing upon loss of CK2 activity. We also identified INCENP and Aurora B, key members of the chromosomal passenger complex (CPC), which associates with the kinesin KIF20A (Hümmer and Mayer, 2009). Previous work has shown that CK2 localizes to the mitotic spindle through interaction with the peptidyl proline isomerase Pin1 (St-Denis et al., 2011). A smaller cluster of interacting proteins (light green) included six members of the RSK ( $\alpha 1-6)$ (90 $\mathrm{kDa}$ ribosomal ribosomal S6 kinase) family of protein kinases which is important for cell growth and differentiation. CK2 has been shown to phosphorylate RPS6KA2 and facilitate its nuclear export (Panasyuk et al., 2006). Consistent with this report, we find that RPS6KA2 as well as the other five members of the RSK family only interact with the $\beta$ subunit. Another subset of interactors (cyan) includes members of the Polycomb repressive complexes (PRC1 and PRC2), including chromobox protein homologs 2 and 8 of PRC1 and SUZ12 of PRC2. CK2 has been shown to phosphorylate members of PRC1 resulting in unconventional transcriptional activation by PRC1 (Gao et al., 2014). However, the interaction and potential regulatory function of CK2 and PRC2 are new, and a role for CK2 in activating or repressing PRC2 has not been described to date. We also identified a cluster of enriched in proteins (yellow) involved in Wnt pathway signaling, including Wnt signal relay disheveled (DVL). CK2 has been shown to interact with and phosphorylate DVL3 resulting in the generation of a docking motif for $\mathrm{CK} 1 \delta / \varepsilon$, which further phosphorylates and activates DVL3 (Bernatik et al., 2011). This cluster also contained the E3ubiquitin ligase Huwe1, a candidate CK2 substrate (serine 2887), which was previously not implicated in CK2 signaling. Finally, we discovered a group of interactors that function in RNA transport (dark green). This group included nuclear pore proteins (NUP98, NUP133, NUP185 and NUP205), mRNA export factors, such as NXF1 and other mRNA processing proteins SLU7, CPSF1, and SMN1.

\section{CK2-PP6 Opposition on Shared Substrates}

In previous work, we have shown that CK2 phosphorylates serine 973/serine 975 on the condensin I subunit NCAPG resulting in its inactivation and that PP6 opposes CK2 on these sites, resulting in condensin I dephosphorylation and activation at the beginning of mitosis (Rusin et al., 2015). Furthermore, we found that PP6 preferentially dephosphorylates serine and threonine residues proximal to acidic residues (similar to the preference for CK2 (SxxE) (Rusin et al., 2015). To extend these findings and to validate specific candidate $\mathrm{CK} 2$ substrates, we performed coupled in vitro kinase-phosphatase assays using purified PP6 and CK2 holoenzyme and candidate substrates (Figure 6A).
For these analyses, we selected proteins with phosphorylation sites that were surrounded by an acidophilic linear kinase motif downstream of the phosphorylatable amino acid and significantly decreased upon CK2 inhibition as well as significantly increased upon PP6c depletion (EF1D, HAP28, S30BP) (Rusin et al., 2015). We generated his-tagged CK2 $\alpha$ and untagged CK2 $\beta$, then coexpressed them and purified CK2 complexes from Spodoptera frugiperda (Sf9) cells. Substrates were expressed in bacteria as histagged constructs. Purified CK2 and substrates were combined in the presence or absence of ATP and incubated at $28^{\circ} \mathrm{C}$ for $2 \mathrm{~h}$ in in vitro kinase assay buffer. Reactions were dialyzed overnight at $4^{\circ} \mathrm{C}$ against in vitro kinase assay buffer without ATP. Purified PP6c was then added or not and reactions were incubated at $28^{\circ} \mathrm{C}$ for $2 \mathrm{~h}$. Reactions were quenched, resolved by SDS-PAGE, gels were Coomassie blue stained and analyzed by LC-MS/MS (Figure 6A). We found that CK2 was able to phosphorylate the candidate CK2 phosphorylation sites detected in our screen in vitro and that the MS2 spectra for these sites match in both the in vivo screen and in vitro kinase assays (Figures 6B-D). Upon addition of PP6, we detected a significant decrease in phosphorylation of these sites (Figures 6E-G). Consistent with our previous findings that PP6 was capable of counteracting CK2 phosphorylation of serine $973 /$ serine 975 on the condensin I subunit NCAPG, PP6 was capable of dephosphorylating other serine and threonine sites proximal to acidic residues in other CK2 substrates, suggesting a more common regulatory mechanism.

\section{Effect of CK2 $\alpha$ Overexpression on Chromosome Condensation}

Previous work from our laboratory and others has shown a role for CK2 in the negative regulation of chromosome condensation through phosphorylation of members of the condensin I complex (Takemoto et al., 2006; Rusin et al., 2015). CK2-dependent phosphorylation of condensin I inhibits its ability to condense chromosomes using a Xenopus laevis in vitro system (Takemoto et al., 2006). Given the identification of several members of the condensin I complex as candidate substrates and interactors of CK2, we determined the effect of CK2 overexpression on chromosome condensation in HeLa cells. To do so, we stably introduced inducible, myc-tagged CK2 $\alpha$ into HeLa cells. Upon addition of doxycycline, expression of CK2 $\alpha$ was induced within $12 \mathrm{~h}$. However, the expression level of exogenous CK2 was low compared to endogenous levels (Supplementary Figure 2). To determine if a slight increase in CK2 $\alpha$ would affect chromosome condensation, we treated cells with nocodazole for $4 \mathrm{~h}$ to arrest them in mitosis and performed chromosome spreads. Cells arrested for prolonged periods of time in mitosis undergo hypercondensation of chromosomes due to the continued action of condensin I. Upon overexpression of CK2 $\alpha$, we detected a small but statistically significant decrease in the percentage of cells with hypercondensed chromosomes, mirroring effects seen with either loss of condensin I members or though inactivation of PP6, which opposes CK2 phosphorylation resulting in the activation of condensin I (Figure 7; Hirota et al., 2004; Rusin et al., 2015). 
A

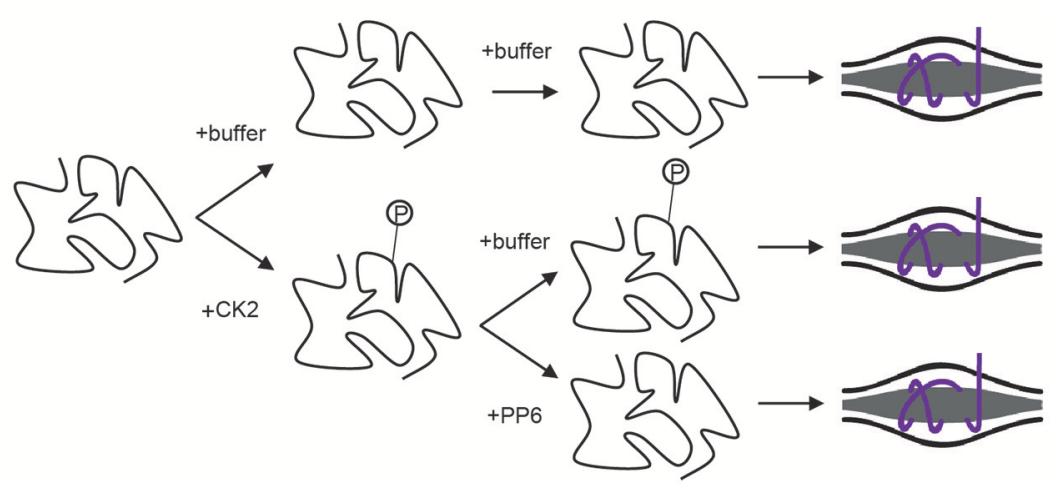

in vitro

kinase assay

in vitro

ppase assay

LC-MS/MS

EF1D pS162

B K.KPATPAEDDEDDDIDLFGpSDNEEEDK.E
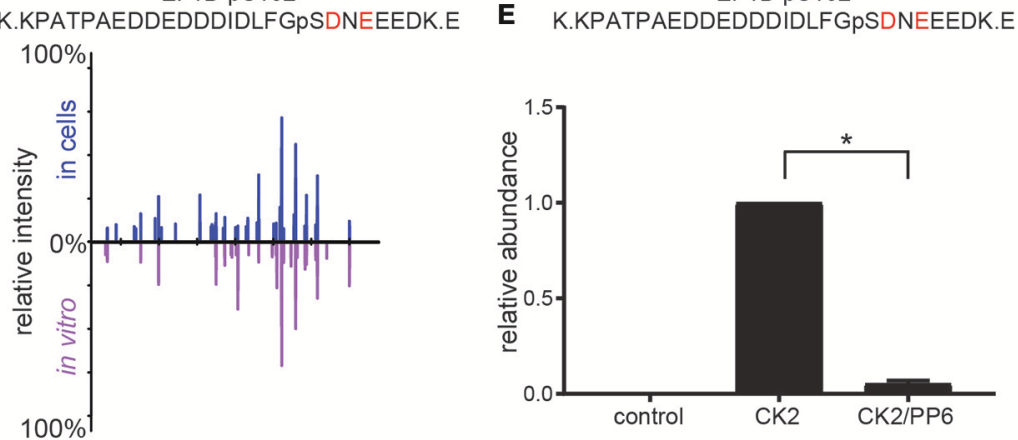

C

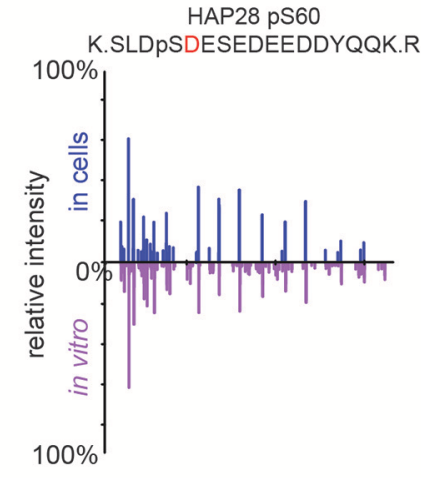

F
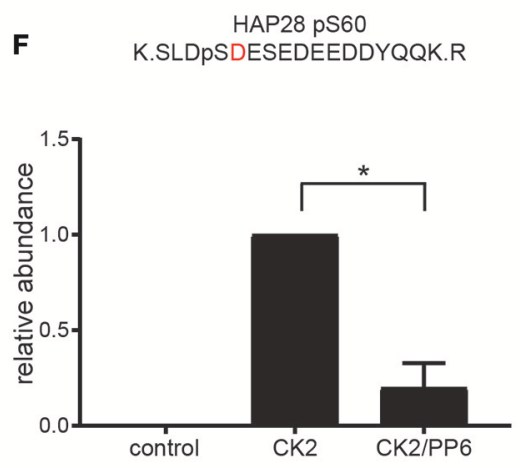

D

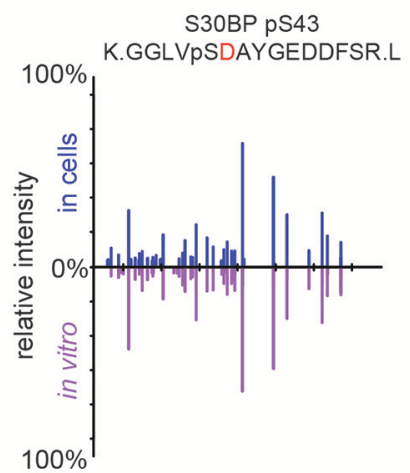

G

S30BP pS43

K.GGLVPSDAYGEDDFSR.L

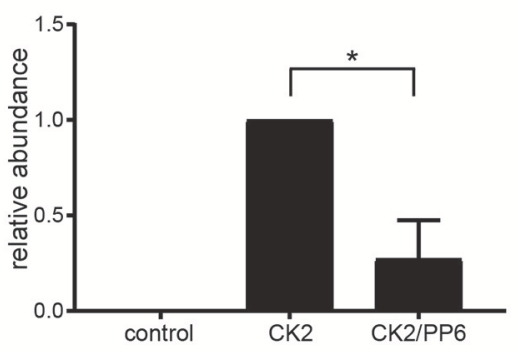

FIGURE 6 | Coupled in vitro kinase and phosphatase workflow and results. (A) Workflow for coupled in vitro kinase and phosphatase assays. Purified substrates were incubated with or without purified CK2 in in vitro kinase assay buffer at $28^{\circ} \mathrm{C}$ for $2 \mathrm{~h}$ and dialyzed overnight against in vitro kinase assay buffer without ATP. Substrates 
FIGURE 6 | were then incubated with or without purified PP6 in in vitro phosphatase buffer at $28^{\circ} \mathrm{C}$ for $2 \mathrm{~h}$, reduced, separated by SDS-PAGE, Coomassie stained, excised, digested with protease, and analyzed by LC-MS/MS. (B-D) Aligned reciprocal tandem mass spectra results for candidate CK2/PP6c substrates from in vivo (top, blue) and in vitro (bottom, purple) analyses. (E-G) Quantification of phosphorylation sites abundance in control, CK2 and CK2 and PP6 treated conditions using Students $T$-test, ${ }^{\star} p<0.05, n=2$ independent experiments for EF1D, 3 for others.
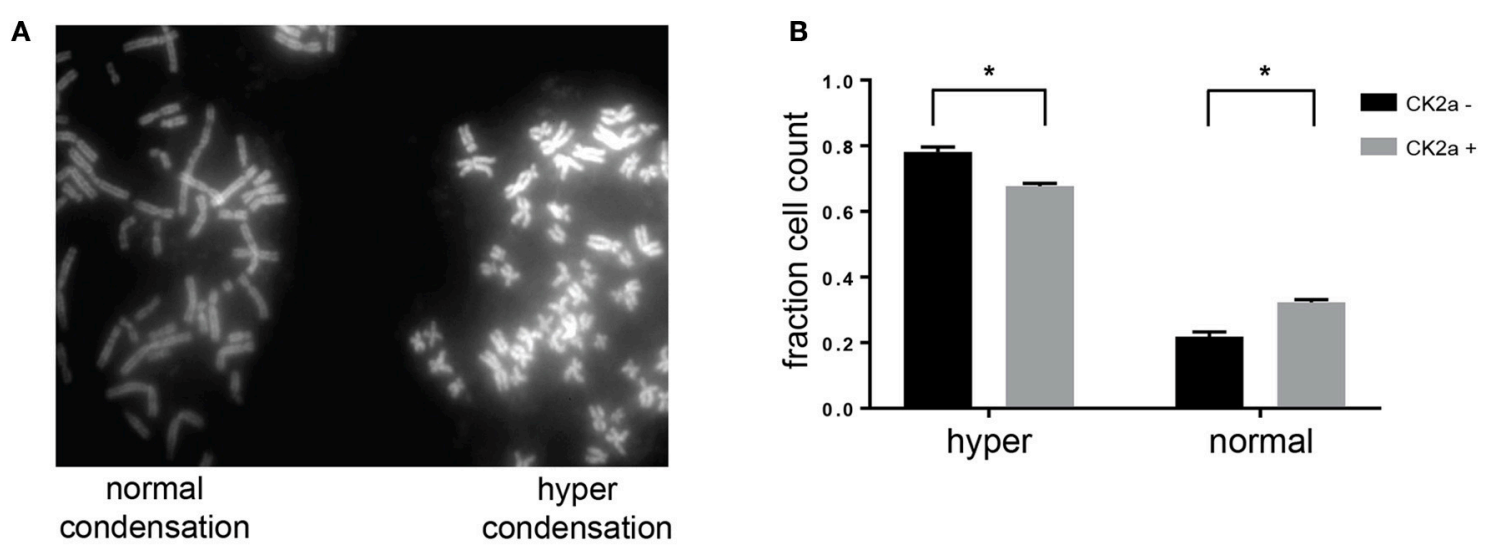

FIGURE 7 | Effects of CK2 on condensin I phosphorylation and activity. (A) Representative image from chromosome spreads depicting normally (left) and hyper (right) condensed chromosomes. (B) Quantification of differences in chromosome condensation between cells with and without overexpression of CK2 $\alpha$, ${ }^{\star} p<0.05, n=3$ independent experiments.

\section{DISCUSSION}

Accurate segregation of genetic material and cellular organelles in mitosis is crucial for the generation of two identical daughter cells. Many of the processes that contribute and control chromosome and organelle segregation are orchestrated via phosphorylation by protein kinases and dephosphorylation by protein phosphatases. Here, we add to the existing knowledge of mitotic kinases and their substrates by interrogating mitotic cells for candidate substrates of the kinase CK2. Using the selective CK2 inhibitor CX-4945 and quantitative mass spectrometry-based phosphoprotemics, we identify 330 phosphorylation sites on 202 proteins as candidate CK2 substrates (Supplementary Table 1). The majority of these sites contained an acidophilic linear kinase motif consistent with the canonical CK2 motif (pS/pT-D/E-X$\mathrm{D} / \mathrm{E}$ ) (Figure 2). Among others, we were able to identify several previously established CK2 substrates in our screen, including EF1D, eIF2 $\beta$, HAP28, Topoisomerase II $\alpha$ and HDAC1 (Shen et al., 1996; Gyenis et al., 2011) confirming the validity of our approach. Candidate CK2 substrates were enriched in biological processes, such as rRNA processing and RNA splicing, cell division and chromatin organization. Consistently, the CK2 interactome was also enriched in these four biological processes among others (Figure 5). Interestingly, we identified candidate CK2 phosphorylation sites on 20 of the proteins identified as specific interactors of CK2 subunits (Supplementary Tables 1, 2). We also confirmed CK2 phosphorylation of specific substrates by in vitro kinase assay (Figure 6) and show a role for CK2 in chromosome condensation in cells.
CK2 has been implicated in the regulation of a plethora of biological processes ranging from transcription and translation to cell survival and cell cycle progression, however, its role in mitosis is still emerging (Nñnez de Villavicencio-Diaz et al., 2017). Our analysis has revealed many new candidate CK2 substrates that need to be explored in future investigations to elaborate the role of CK2 in mitosis. While our analysis was conducted under mitotic arrest condition, it is possible that CK2 phosphorylates some of these candidate substrates also in other cell cycle phases. In contrast to other mitotic kinases, including Aurora kinase A and B, Polo-like kinase 1, and Cyclin-dependent kinase 1, whose activities are tightly controlled and limited to mitosis, CK2's activity is thought to be constitutively active (Pinna, 2002; van de Weerdt and Medema, 2006; Salaun et al., 2008; Turowec et al., 2010). Thus, candidate mitotic substrate expressed in other cell cycle phases could be phosphorylated by CK2 outside of mitosis.

Understanding mitotic progression requires not only knowledge of mitotic kinase substrates and their temporal and spatially resolved phosphorylation patterns, but also the counteraction and reversal of these phosphorylation sites by protein phosphatases. While research efforts over the last decade have revealed many kinase substrates, counteracting phosphatases and the shared substrates that link kinases and phosphatases are often elusive. The majority of dephosphorylation in interphase as well as mitosis is carried out by the family of phosphoprotein phosphatases (PPP) (Shi, 2009). We have previously reported that PP6, but not PP2A, opposes CK2 on specific phosphorylation sites (Rusin et al., 2015). We further extend these observations here, showing that opposition of CK2 by PP6 might be a 
more general mechanism. This is of significant interest, as no other member of the PPP family has been described so far to dephosphorylate acidophilic sites (Wurzenberger and Gerlich, 2011). Furthermore, a counteraction of the Saccharomyces cerevisiae homologs of PP6c and casein kinase, Sit4 and Hrr25, respectively, has been described for the regulation of the elongator complex (Mehlgarten et al., 2009). Connecting kinases and phosphatases on their shared substrates is essential for completing our understanding of cellular signaling. Follow-up studies of these candidate substrates are necessary to further clarify CK2-PP6 dependent substrate interactions and establish the biological significance of these findings.

In summary, the work performed here expands upon the current knowledge of CK2 substrates and functions in mitosis and potentially other cell cycle phases, and provides a resource to begin exploring the largely unknown role of this prolific kinase in a crucial cell cycle phase.

\section{AUTHOR CONTRIBUTIONS}

SR performed the CK2 inhibitor phosphoproteomics and interactome experiments as well as in vitro kinase and phosphatase assays and chromosome spreads. MA managed data files and the data pipeline for all proteomics experiments and generated software for iBAQ quantification. AK designed the study. SR and AK analyzed the data. SR generated the figures. SR and AK wrote the manuscript.

\section{REFERENCES}

Abe, S., Nagasaka, K., Hirayama, Y., Kozuka-Hata, H., Oyama, M., Aoyagi, Y., et al. (2011). The initial phase of chromosome condensation requires Cdk1mediated phosphorylation of the CAP-D3 subunit of condensin II. Genes Dev. 25, 863-874. doi: 10.1101/gad.2016411

Ahmed, K. (1999). Nuclear matrix and protein kinase CK2 signaling. Crit. Rev. Eukaryot. Gene Expr. 9, 329-336. doi: 10.1615/CritRevEukarGeneExpr.v9.i3-4.170

Ahmed, K., Gerber, D. A., and Cochet, C. (2002). Joining the cell survival squad: an emerging role for protein kinase CK2. Trends Cell Biol. 12, 226-230. doi: 10.1016/S0962-8924(02)02279-1

Barrett, R. M., Colnaghi, R., and Wheatley, S. P. (2011). Threonine 48 in the BIR domain of survivin is critical to its mitotic and anti-apoptotic activities and can be phosphorylated by CK2 in vitro. Cell Cycle 10, 538-548. doi: $10.4161 /$ cc. 10.3 .14758

Barz, T., Ackermann, K., Dubois, G., Eils, R., and Pyerin, W. (2003). Genome-wide expression screens indicate a global role for protein kinase CK2 in chromatin remodeling. J. Cell Sci. 116(Pt 8), 1563-1577. doi: 10.1242/jcs.00352

Bernatik, O., Ganji, R. S., Dijksterhuis, J. P., Konik, P., Cervenka, I., and Bryja, V. (2011). Sequential activation and inactivation of Dishevelled in the Wnt/beta-catenin pathway by casein kinases. J. Biol. Chem. 286, 10396-10410. doi: $10.1074 /$ jbc.M110.169870

Chou, M. F., and Schwartz, D. (2011). Biological sequence motif discovery using motif-x. Curr. Protoc. Bioinformatics Chapter 13: Unit 13.15-24. doi: 10.1002/0471250953.bi1315s35

Cohen, P. (2000). The regulation of protein function by multisite phosphorylation-a 25 year update. Trends Biochem. Sci. 25, 596-601. doi: 10.1016/S0968-0004(00)01712-6

\section{FUNDING}

This work was supported by grants from NIH/NIGMS (R35GM119455, P20GM113132) and The V Foundation for Cancer Research (V2016-022) to AK and from NIH/NIGMS (T32GM008704) to SR.

\section{ACKNOWLEDGMENTS}

We thank members of the Kettenbach and Gerber labs for helpful discussions. We also thank Andrew Grassetti for generation of $\mathrm{R}$ scripts for plotting MS2 spectra in Figure 6 and Scott Gerber for critical discussions of the data and the manuscript.

\section{SUPPLEMENTARY MATERIAL}

The Supplementary Material for this article can be found online at: https://www.frontiersin.org/articles/10.3389/fcell.2017. 00097/full\#supplementary-material

Supplementary Figure 1 | Experimental design of CK2 phosphoproteomic analysis.

Supplementary Figure $\mathbf{2}$ | Inducible CK2 $\alpha$ protein expression in HeLa FLP cells. Western blot using $\alpha-\mathrm{CK} 2 \alpha$ antibody antibody of HeLa FLP and HeLa FLP- CK2 $\alpha$ expressing cells in the presence and absence of doxycycline.

Supplementary Table 1 | Data of phosphoproteomics analysis of CX-4945 treated, mitotically-arrested HeLa cells.

Supplementary Table 2 | Data of CK2 AP-MS analysis.

Crooks, G. E., Hon, G., Chandonia, J. M., and Brenner, S. E. (2004). WebLogo: a sequence logo generator. Genome Res. 14, 1188-1190. doi: 10.1101/gr.8 49004

Daum, J. R., and Gorbsky, G. J. (1998). Casein kinase II catalyzes a mitotic phosphorylation on threonine 1342 of human DNA topoisomerase IIalpha, which is recognized by the $3 \mathrm{~F} 3 / 2$ phosphoepitope antibody. J. Biol. Chem. 273, 30622-30629. doi: 10.1074/jbc.273.46. 30622

Deplus, R., Blanchon, L., Rajavelu, A., Boukaba, A., Defrance, M., Luciani, J., et al. (2014). Regulation of DNA methylation patterns by CK2-mediated phosphorylation of Dnmt3a. Cell Rep. 8, 743-753. doi: 10.1016/j.celrep.2014.06.048

Elias, J. E., and Gygi, S. P. (2007). Target-decoy search strategy for increased confidence in large-scale protein identifications by mass spectrometry. Nat. Methods 4, 207-214. doi: 10.1038/nmeth1019

Eng, J. K., Jahan, T. A., and Hoopmann, M. R. (2013). Comet: an opensource MS/MS sequence database search tool. Proteomics 13, 22-24. doi: 10.1002/pmic.201200439

Escargueil, A. E., Plisov, S. Y., Filhol, O., Cochet, C., and Larsen, A., K. (2000). Mitotic phosphorylation of DNA topoisomerase II alpha by protein kinase CK2 creates the MPM-2 phosphoepitope on Ser-1469. J. Biol. Chem. 275, 34710-34718. doi: 10.1074/jbc.M005 179200

Floyd, S., Pines, J., and Lindon, C. (2008). APC/C Cdh1 targets aurora kinase to control reorganization of the mitotic spindle at anaphase. Curr. Biol. 18, 1649-1658. doi: 10.1016/j.cub.2008.09.058

Gao, Z., Lee, P., Stafford, J. M., von Schimmelmann, M., Schaefer, A., and Reinberg, D. (2014). An AUTS2-Polycomb complex activates gene expression in the CNS. Nature 516, 349-354. doi: 10.1038/nature13921 
Glover, C. V. (1998). On the physiological role of casein kinase II in Saccharomyces cerevisiae. Prog. Nucleic Acid Res. Mol. Biol. 59, 95-133. doi: 10.1016/S0079-6603(08)61030-2

Grassetti, A. V., Hards, R., and Gerber, S. A. (2017). Offline pentafluorophenyl (PFP)-RP prefractionation as an alternative to high-pH RP for comprehensive LC-MS/MS proteomics and phosphoproteomics. Anal. Bioanal. Chem. 409, 4615-4625. doi: 10.1007/s00216-017-0407-6

Gu, L., Husain-Ponnampalam, R., Hoffmann-Benning, S., and Henry, R. W. (2007). The protein kinase CK2 phosphorylates SNAP190 to negatively regulate SNAPC DNA binding and human U6 transcription by RNA polymerase III. J. Biol. Chem. 282, 27887-27896. doi: 10.1074/jbc.M702269200

Guerra, B., and Issinger, O. G. (1999). Protein kinase CK2 and its role in cellular proliferation, development and pathology. Electrophoresis 20, 391-408.

Gyenis, L., Duncan, J. S., Turowec, J. P., Bretner, M., and Litchfield, D. W. (2011). Unbiased functional proteomics strategy for protein kinase inhibitor validation and identification of bona fide protein kinase substrates: application to identification of EEF1D as a substrate for CK2. J. Proteome Res. 10, 4887-4901. doi: 10.1021/pr2008994

Hanahan, D., and Weinberg, R. A. (2011). Hallmarks of cancer: the next generation. Cell 144, 646-674. doi: 10.1016/j.cell.2011.02.013

Hanif, I. M., Shazib, M. A., Ahmad, K. A., and Pervaiz, S. (2010). Casein Kinase II: an attractive target for anti-cancer drug design. Int. J. Biochem. Cell Biol. 42, 1602-1605. doi: 10.1016/j.biocel.2010.06.010

Hériché, J. K., Lebrin, F., Rabilloud, T., Leroy, D., Chambaz, E. M., and Goldberg, Y. (1997). Regulation of protein phosphatase 2A by direct interaction with casein kinase $2 \alpha$. Science 276, 952-955. doi: 10.1126/science.276.5314.952

Hirota, T., Gerlich, D., Koch, B., Ellenberg, J., and Peters, J. M. (2004). Distinct functions of condensin I and II in mitotic chromosome assembly. J. Cell Sci. 117(Pt 26), 6435-6445. doi: 10.1242/jcs.01604

Hornbeck, P. V., Zhang, B., Murray, B., Kornhauser, J. M., Latham, V., and Skrzypek, E. (2015). PhosphoSitePlus, 2014: mutations, PTMs and recalibrations. Nucleic Acids Res. 43, D512-D520. doi: 10.1093/nar/gku1267

Hümmer, S., and Mayer, T. U. (2009). Cdk1 negatively regulates midzone localization of the mitotic kinesin Mklp2 and the chromosomal passenger complex. Curr. Biol. 19, 607-612. doi: 10.1016/j.cub.2009.02.046

Jiang, K., Rezabkova, L., Hua, S., Liu, Q., Capitani, G., Altelaar, A. F., et al. (2017). Microtubule minus-end regulation at spindle poles by an ASPM-katanin complex. Nat. Cell Biol. 19, 480-492. doi: 10.1038/ncb3511

Kettenbach, A. N., and Gerber, S. A. (2011). Rapid and reproducible singlestage phosphopeptide enrichment of complex peptide mixtures: application to general and phosphotyrosine-specific phosphoproteomics experiments. Anal. Chem. 83, 7635-7644. doi: 10.1021/ac201894j

Kettenbach, A. N., Schweppe, D. K., Faherty, B. K., Pechenick, D., Pletnev, A. A., and Gerber, S. A. (2011). Quantitative phosphoproteomics identifies substrates and functional modules of Aurora and Polo-like kinase activities in mitotic cells. Sci. Signal 4:rs5. doi: 10.1126/scisignal.2001497

Khan, D. H., He, S., Yu, J., Winter, S., Cao, W., Seiser, C., et al. (2013). Protein kinase CK2 regulates the dimerization of histone deacetylase 1 (HDAC1) and HDAC2 during mitosis. J. Biol. Chem. 288, 16518-16528. doi: $10.1074 /$ jbc.M112.440446

Kim, H., Choi, K., Kang, H., Lee, S. Y., Chi, S. W., Cho, S., et al. (2014). Identification of a novel function of CX-4945 as a splicing regulator. PLoS ONE 9:e94978. doi: 10.1371/journal.pone.0094978

Korrodi-Gregório, L., Ferreira, M., Vintém, A. P., Wu, W., Muller, T., Marcus, K., et al. (2013). Identification and characterization of two distinct PPP1R2 isoforms in human spermatozoa. BMC Cell Biol. 14:15. doi: 10.1186/1471-2121-14-15

Kos-Braun, I. C., Jung, I., and Koš, M. (2017). Tor1 and CK2 kinases control a switch between alternative ribosome biogenesis pathways in a growthdependent manner. PLoS Biol. 15:e2000245. doi: 10.1371/journal.pbio.2000245

Lee, M., Dworkin, A. M., Lichtenberg, J., Patel, S. J., Trivedi, N. S., Gildea, D., et al. (2014). Metastasis-associated protein ribosomal RNA processing 1 homolog B (RRP1B) modulates metastasis through regulation of histone methylation. Mol. Cancer Res. 12, 1818-1828. doi: 10.1158/1541-7786.MCR-14-0167

Lehnert, S., Götz, C., Kartarius, S., Schäfer, B., and Montenarh, M. (2008). Protein kinase CK2 interacts with the splicing factor hPrp3p. Oncogene 27, 2390-2400. doi: 10.1038/si.onc. 1210882
Li, H., Liu, X. S., Yang, X., Wang, Y., Wang, Y., Turner, J. R., et al. (2010). Phosphorylation of CLIP-170 by Plk1 and CK2 promotes timely formation of kinetochore-microtubule attachments. EMBO J. 29, 2953-2965. doi: $10.1038 /$ emboj.2010.174

Litchfield, D. W. (2003). Protein kinase CK2: structure, regulation and role in cellular decisions of life and death. Biochem. J. 369(Pt 1) 1-15. doi: 10.1042/bj20021469

Litchfield, D. W., and Lüscher, B. (1993). Casein kinase II in signal transduction and cell cycle regulation. Mol. Cell. Biochem. 127-128, 187-199. doi: 10.1007/BF01076770

Llorens, F., Duarri, A., Sarró, E., Roher, N., Plana, M., and Itarte, E. (2006). The N-terminal domain of the human eIF2 $\beta$ subunit and the CK2 phosphorylation sites are required for its function. Biochem. J. 394(Pt 1), 227-236. doi: 10.1042/BJ20050605

Lorenz, P., Pepperkok, R., Ansorge, W., and Pyerin, W. (1993). Cell biological studies with monoclonal and polyclonal antibodies against human casein kinase II subunit beta demonstrate participation of the kinase in mitogenic signaling. J. Biol. Chem. 268, 2733-2739.

Maiti, T., Bandyopadhyay, A., and Maitra, U. (2003). Casein kinase II phosphorylates translation initiation factor 5 (eIF5) in Saccharomyces cerevisiae. Yeast 20, 97-108. doi: 10.1002/yea.937

Marin, O., Meggio, F., Draetta, G., and Pinna, L. A. (1992). The consensus sequences for cdc2 kinase and for casein kinase-2 are mutually incompatible. A study with peptides derived from the beta-subunit of casein kinase-2. FEBS Lett. 301, 111-114. doi: 10.1016/0014-5793(92) 80221-2

Marin, O., Meggio, F., Marchiori, F., Borin, G., and Pinna, L. A. (1986). Site specificity of casein kinase-2 (TS) from rat liver cytosol. A study with model peptide substrates. Eur. J. Biochem. 160, 239-244. doi: 10.1111/j.1432-1033.1986.tb09962.x

Meggio, F., Marin, O., and Pinna, L. A. (1994). Substrate specificity of protein kinase CK2. Cell. Mol. Biol. Res. 40, 401-409.

Mehlgarten, C., Jablonowski, D., Breunig, K. D., Stark, M. J., and Schaffrath, R. (2009). Elongator function depends on antagonistic regulation by casein kinase Hrr25 and protein phosphatase Sit4. Mol. Microbiol. 73, 869-881. doi: 10.1111/j.1365-2958.2009.06811.x

Neef, R., Preisinger, C., Sutcliffe, J., Kopajtich, R., Nigg, E. A., Mayer, T. U., et al. (2003). Phosphorylation of mitotic kinesin-like protein 2 by polo-like kinase 1 is required for cytokinesis. J. Cell Biol. 162, 863-875. doi: 10.1083/jcb.2003 06009

Niefind, K., Guerra, B., Ermakowa, I., and Issinger, O. G. (2001). Crystal structure of human protein kinase CK2: insights into basic properties of the CK2 holoenzyme. EMBO J. 20, 5320-5331. doi: 10.1093/emboj/20.1 9.5320

Nuñez de Villavicencio-Diaz, T., Rabalski, A. J., and Litchfield, D. W. (2017). Protein Kinase CK2: intricate relationships within regulatory cellular networks. Pharmaceuticals 10:E27. doi: 10.3390/ph10010027

Ong, S. E., Blagoev, B., Kratchmarova, I. Kristensen, D. B., Steen, H., Pandey, A., et al. (2002). Stable isotope labeling by amino acids in cell culture, SILAC, as a simple and accurate approach to expression proteomics. Mol. Cell. Proteomics 1, 376-386. doi: 10.1074/mcp.M200025-MCP200

Ottaviano, Y., and Gerace, L. (1985). Phosphorylation of the nuclear lamins during interphase and mitosis. J. Biol. Chem. 260, 624-632.

Panasyuk, G., Nemazanyy, I., Zhyvoloup, A., Bretner, M., Litchfield, D. W., Filonenko, V., et al. (2006). Nuclear export of S6K1 II is regulated by protein kinase CK2 phosphorylation at Ser-17. J. Biol. Chem. 281, 31188-31201. doi: 10.1074/jbc.M602618200

Park, G. H., Lee, Y. T., and Bae, Y. S. (2001). Stimulation of human DNA topoisomerase II activity by its direct association with the beta subunit of protein kinase CKII. Mol. Cells 11, 82-88.

Peng, Y., Wong, C. C., Nakajima, Y., Tyers, R. G., Sarkeshik, A. S., Yates, J. III., et al. (2011). Overlapping kinetochore targets of CK2 and Aurora B kinases in mitotic regulation. Mol. Biol. Cell 22, 2680-2689. doi: 10.1091/mbc.E10-11-0915

Pepperkok, R., Lorenz, P., Ansorge, W., and Pyerin, W. (1994). Casein kinase II is required for transition of G0/G1, early G1, and G1/S phases of the cell cycle. J. Biol. Chem. 269, 6986-6991. 
Pepperkok, R., Lorenz, P., Jakobi, R., Ansorge, W., and Pyerin, W. (1991). Cell growth stimulation by EGF: inhibition through antisenseoligodeoxynucleotides demonstrates important role of casein kinase II. Exp. Cell Res. 197, 245-253. doi: 10.1016/0014-4827(91)90429-X

Perea, S. E., Reyes, O., Baladron, I., Perera, Y., Farina, H., Gil, J., Rodriguez, A., et al. (2008). CIGB-300, a novel proapoptotic peptide that impairs the CK2 phosphorylation and exhibits anticancer properties both in vitro and in vivo. Mol. Cell. Biochem. 316, 163-167. doi: 10.1007/s11010-008-9814-5

Petrone, A., Adamo, M. E., Cheng, C., and Kettenbach, A. N. (2016). Identification of candidate cyclin-dependent kinase 1 (Cdk1) substrates in mitosis by quantitative phosphoproteomics. Mol. Cell. Proteomics 15, 2448-2461. doi: 10.1074/mcp.M116.059394

Pinna, L. A. (2002). Protein kinase CK2: a challenge to canons. J. Cell Sci. 115(Pt 20), 3873-3878. doi: 10.1242/jcs.00074

Pinna, L. A., and Meggio, F. (1997). Protein kinase CK2 (“casein kinase-2”) and its implication in cell division and proliferation. Prog. Cell Cycle Res. 3, 77-97. doi: 10.1007/978-1-4615-5371-7_7

Rajagopalan, H., and Lengauer, C. (2004). Aneuploidy and cancer. Nature 432, 338-341. doi: 10.1038/nature03099

Rusin, S. F., Schlosser, K. A., Adamo, M. E., and Kettenbach, A. N. (2015). Quantitative phosphoproteomics reveals new roles for the protein phosphatase PP6 in mitotic cells. Sci. Signal 8:rs12. doi: 10.1126/scisignal. aab3138

Saito, R., Smoot, M. E., Ono, K., Ruscheinski, J., Wang, P., L., Lotia, S., et al. (2012). A travel guide to Cytoscape plugins. Nat. Methods 9, 1069-1076. doi: $10.1038 /$ nmeth. 2212

Salaun, P., Rannou, Y., and Prigent, C. (2008). Cdk1, Plks, Auroras, and Neks: the mitotic bodyguards. Adv. Exp. Med. Biol. 617, 41-56. doi: 10.1007/978-0-387-69080-3_4

Santamaria, A., Wang, B., Elowe, S., Malik, R., Zhang, F., Bauer, M., et al. (2011). The Plk1-dependent phosphoproteome of the early mitotic spindle. Mol. Cell. Proteomics 10:M110.004457. doi: 10.1074/mcp.M110.004457

Schwartz, D., and Gygi, S. P. (2005). An iterative statistical approach to the identification of protein phosphorylation motifs from large-scale data sets. Nat. Biotechnol. 23, 1391-1398. doi: 10.1038/nbt1146

Shannon, P., Markiel, A., Ozier, O., Baliga, N. S., Wang, J. T., Ramage D., et al. (2003). Cytoscape: a software environment for integrated models of biomolecular interaction networks. Genome Res. 13, 2498-2504. doi: 10.1101/gr.1239303

Sharma, K., D’Souza, R. C., Tyanova, S., Schaab, C., Wiśniewski, J. R., Cox, J., et al. (2014). Ultradeep human phosphoproteome reveals a distinct regulatory nature of Tyr and Ser/Thr-based signaling. Cell Rep. 8, 1583-1594. doi: 10.1016/j.celrep.2014.07.036

Shen, L., Huang, K. P., Chen, H. C., and Huang, F. L. (1996). Molecular cloning and characterization of a novel casein kinase II substrate, HASPP28, from rat brain. Arch. Biochem. Biophys. 327, 131-141. doi: 10.1006/abbi.199 6.0101

Shi, Y. (2009). Serine/threonine phosphatases: mechanism through structure. Cell 139, 468-484. doi: 10.1016/j.cell.2009.10.006

Siddiqui-Jain, A., Drygin, D., Streiner, N., Chua, P., Pierre, F., O'Brien, S., et al. (2010). CX-4945, an orally bioavailable selective inhibitor of protein kinase CK2, inhibits prosurvival and angiogenic signaling and exhibits antitumor efficacy. Cancer Res. 70, 10288-10298. doi: 10.1158/0008-5472.CAN-1 $0-1893$

St-Denis, N. A., Bailey, M. L., Parker, E. L., Vilk, G., and Litchfield, D. W. (2011). Localization of phosphorylated CK2 $\alpha$ to the mitotic spindle requires the peptidyl-prolyl isomerase Pin1. J. Cell Sci. 124 (Pt 14), 2341-2348. doi: $10.1242 /$ jcs.077446
St-Denis, N. A., Derksen, D. R., and Litchfield, D. W. (2009). Evidence for regulation of mitotic progression through temporal phosphorylation and dephosphorylation of CK2 $\alpha$. Mol. Cell. Biol. 29, 2068-2081. doi: 10.1128/MCB.01563-08

St-Denis, N., Gabriel, M., Turowec, J. P., Gloor, G. B., Li, S. S., Gingras A. C., et al. (2015). Systematic investigation of hierarchical phosphorylation by protein kinase CK2. J. Proteomics 118, 49-62. doi: 10.1016/j.jprot.2014.10.020

Szklarczyk, D., Franceschini, A., Wyder, S., Forslund, K., Heller, D., HuertaCepas, J., et al. (2015). STRING v10: protein-protein interaction networks, integrated over the tree of life. Nucleic Acids Res. 43, D447-D452. doi: 10.1093/nar/gku1003

Takemoto, A., Kimura, K., Yanagisawa, J., Yokoyama, S., and Hanaoka, F. (2006). Negative regulation of condensin I by CK2-mediated phosphorylation. EMBO J. 25, 5339-5348. doi: 10.1038/sj.emboj.7601394

Taus, T., Köcher, T., Pichler, P., Paschke, C., Schmidt, A., Henrich, C., et al. (2011). Universal and confident phosphorylation site localization using phosphoRS. J. Proteome Res. 10, 5354-5362. doi: 10.1021/pr200611n

Tawfic, S., Yu, S., Wang, H., Faust, R., Davis, A., and Ahmed, K. (2001). Protein kinase CK2 signal in neoplasia. Histol. Histopathol. 16, 573-582.

Theis-Febvre, N., Filhol, O., Froment, C., Cazales, M., Cochet, C., Monsarrat, B., et al. (2003). Protein kinase CK2 regulates CDC25B phosphatase activity. Oncogene 22, 220-232. doi: 10.1038/sj.onc.1206107

Tsai, S. C., and Seto, E. (2002). Regulation of histone deacetylase 2 by protein kinase CK2. J. Biol. Chem. 277, 31826-31833. doi: 10.1074/jbc.M2041 49200

Turowec, J. P., Duncan, J. S., French, A. C., Gyenis, L., St Denis, N., A., Vilk, G., et al. (2010). Protein kinase CK2 is a constitutively active enzyme that promotes cell survival: strategies to identify CK2 substrates and manipulate its activity in mammalian cells. Meth. Enzymol. 484, 471-493. doi: 10.1016/B978-0-12-381298-8.00023-X

Valot, B., Langella, O., Nano, E., and Zivy, M. (2011). MassChroQ: a versatile tool for mass spectrometry quantification. Proteomics 11, 3572-3577. doi: $10.1002 /$ pmic. 201100120

van de Weerdt, B. C., and Medema, R. H. (2006). Polo-like kinases: a team in control of the division. Cell Cycle 5, 853-864. doi: 10.4161/cc.5.8.2692

Wurzenberger, C., and Gerlich, D. W. (2011). Phosphatases: providing safe passage through mitotic exit. Nat. Rev. Mol. Cell Biol. 12, 469-482. doi: 10.1038/nrm3149

Yde, C. W., Olsen, B. B., Meek, D., Watanabe, N., and Guerra, B. (2008). The regulatory beta-subunit of protein kinase CK2 regulates cell-cycle progression at the onset of mitosis. Oncogene 27, 4986-4997. doi: 10.1038/onc.2008.146

Yoh, S. M., Cho, H., Pickle, L., Evans, R. M., and Jones, K. A. (2007). The Spt6 SH2 domain binds Ser2-P RNAPII to direct Iws1-dependent mRNA splicing and export. Genes Dev. 21, 160-174. doi: 10.1101/gad.1503107

Zhang, X., Zhang, H., and Wang, Y. (2014). Phosphorylation regulates VCIP135 function in Golgi membrane fusion during the cell cycle. J. Cell Sci. 127(Pt 1), 172-181. doi: 10.1242/jcs. 134668

Conflict of Interest Statement: The authors declare that the research was conducted in the absence of any commercial or financial relationships that could be construed as a potential conflict of interest.

Copyright (C) 2017 Rusin, Adamo and Kettenbach. This is an open-access article distributed under the terms of the Creative Commons Attribution License (CC BY). The use, distribution or reproduction in other forums is permitted, provided the original author(s) or licensor are credited and that the original publication in this journal is cited, in accordance with accepted academic practice. No use, distribution or reproduction is permitted which does not comply with these terms. 